IFN Working Paper No. 730, 2008

\title{
Trading Profiles and Developing Country Participation in the WTO Dispute Settlement System
}

Joseph Francois, Henrik Horn and Niklas Kaunitz 


\title{
Trading Profiles and Developing Country Participation in the WTO Dispute Settlement System
}

\author{
Joseph Francois $^{*}$, Henrik Horn ${ }^{* *}$ and Niklas Kaunitz ${ }^{* * *}$
}

October 2007

\begin{abstract}
It has been alleged since its inception that the WTO Dispute Settlement (DS) mechanism is biased against developing countries, as manifested in e.g. allegedly too low rates of dispute initiation. To shed light on this issue, this study analyses the determinants of developing country participation in the DS system, using bilateral industry-level trade data, and a data set on dispute initiation that is significantly richer than what has been employed in the literature. But the study also points to a number of fundamental conceptual and data problems that beset the whole empirical literature that seeks to draw policy conclusions based on country participation in the DS system. While perhaps appreciated by researchers working in this area, these problems appear to go unnoticed by practitioners drawing on this literature.
\end{abstract}

Keywords: WTO, dispute settlement, developing countries, dispute initiation JEL: $\quad$ F13 F53 O19

This study has been prepared for the International Centre for Trade and Sustainable Development and the Geneva International Academic Network. Helpful comments on earlier drafts by Christophe Bellman, Johannes Bernabe, Carsten Fink, and Greg Shaffer are gratefully acknowledged. We gratefully acknowledge financial support from the Marianne and Marcus Wallenberg Foundation.

\footnotetext{
* Johannes Kepler University, Linz; CEPR, London.

${ }^{* *}$ Research Institute of Industrial Economics (IFN), Stockholm; Bruegel, Brussels; CEPR, London.

*** Research Institute of Industrial Economics (IFN), Stockholm.
} 
Trading Profiles and Developing Country Participation

in the WTO Dispute Settlement System

Non-technical Summary

There has been an undercurrent of worry around the WTO DS mechanism since its inception. In particular, it has been alleged that the system is biased against developing countries. On the basis of this worry, there have been proposals for reform of the system to remedy perceived biases, particularly in dispute initiation. The starting point of research in this area is therefore a seemingly simple question. "Do developing countries use the DS mechanism less than they 'should' based on objective criteria?”

In our empirical analysis, we have tried to highlight aspects of this question, by improving on the earlier literature in several respects. First, we use a much richer dispute data set than has been used so far in the literature, by including all dispute initiation during the period 1995-2006. Second, we focus more on the role of industrial structure than has been done in the literature. Third, we employ econometric techniques that, while not entirely new in the field, are more suitable to the situation at hand than what is often used. Our results suggest that the composition of trade, the volume of trade, income levels, aid levels, and legal capacity, explain the observed aggregate level of dispute initiation fairly well. Predictions from the empirical model also suggest that Low Income Developing countries (this group excludes least developed countries), have launched more complaints than they should have, based on these characteristics.

Fourth, we use the estimated model to answer two fundamental questions concerning the determinants of Least Developed Country (LDC) participation as complainants, questions that to the best of our knowledge have not been highlighted in the literature. Our first question concerns the role of economic country size. It is often said that since LDCs typically are very small in terms of GDP, in terms of trade, etc, that they do not have incentives to launch disputes. We therefore make the thought-experiment of merging all LDCs into an "LDC Union” for the handling of complaints in the DS system. This Union is instructed to base its decisions concerning litigation on the combined exports of its members, and would draw on the combined resources of the countries in other respects. The model predicts that a country with the characteristics of this "LDC Union" would have 
initiated roughly twice as many disputes as the model predicts that this group of countries would have launched if acting individually. One should be careful not to over-emphasize the validity of this magnitude. More interesting is that this experiment suggests that LDCs may have so few disputes not only because of small trade volumes, or because of small GDP levels, but also because of the interaction between such explanatory factors.

The second question we examine is the common perception in the policy literature that the LDC trade composition explains their seemingly low participation rates. To this end we make the further thought experiment of letting the export structure of this "LDC Union” be the same as the average of the exports of G2, Earlier Industrialized and Newly Industrialized countries, while keeping the total volume of exports unchanged. This "LDC Union” is hence in terms of industry export structure a replica of the richer countries, but is in other respects an aggregation of LDCs. Using the estimated model, this change in export composition would have a fairly limited impact on dispute initiation by LDC, contrary to what is often suggested. In other words, the composition of trade does not appear to be a determining factor.

We would finally like to emphasize the great caution that is needed when drawing policy conclusions based on observations concerning dispute initiation in the DS system. Such conclusions are inevitably based on a number of special assumptions that are typically not made explicit. For instance, there are conceptual problems with regard to the definition of the unit of account ("a dispute”) as well as relevant benchmarks, there are econometric problems with regard to how to distinguish the determinants of dispute initiation as well as how to handle the dominance of zeros in the data, there are data availability problems with regard to a number of important variables such as legal capacity and power. In addition, there are conceptual problems with regard to how to frame relevant and well-defined questions that can be answered within the model. We have here tried to address some of these problems, but many still remain. 


\section{Introduction}

The role of developing countries in the dispute settlement mechanisms of the multilateral trading system has steadily increased during the last 15 years. There are probably several reasons for this increasing interest. One is the dramatic increase in developing country membership, which today accounts for the vast majority of members of the World Trade Organization (WTO). Another reason is the hopes attached to the creation of the dispute settlement (DS) mechanism of the WTO, which was intended to be less dependent on political or diplomatic solutions, and more on formal legal procedures. Yet another reason for the increased interest in the working of the DS mechanism is the increased reliance during this period on trade liberalization as a means of enhancing development. A core issue in this debate has been the limited use of the WTO DS mechanism by developing countries. Over the last decade, a burgeoning academic literature (mainly in economics and political science) has focused on the extent to which developing countries can be said to be underrepresented, and if so, what the reasons are for their relatively limited participation.

Three themes can be said to dominate this literature. One is the notion that the use of the DS system largely reflects commercial interests. The limited participation of developing countries, and in particular least developed countries, would according to this view reflect their smaller trade flows. For example, Horn et al (1999) show that the distribution of the actual disputes for the years 1995-98 across the Members of the WTO closely corresponds to the structure of global trade, leaving very little to be explained by other factors. A second theme is that low participation by developing countries reflects their limited legal and administrative capacity to identify illegalities, and to pursue complaints, and/or their inability to purchase such services from e.g. law firms. A third theme, often denoted the "power hypothesis", is that developing countries abstain from launching complaints either from a fear that they will face retaliation by richer adversaries, or from a belief that they will not be able to enforce rulings by WTO courts in their favor. These three explanations of developing country participation are of course not mutually exclusive, and our understanding is that while authors may at times put particular emphasis on the findings of their own studies, there is a general agnosticism concerning their relative importance. Characteristic of all three types of explanations of the low participation rate of developing countries - trade structure, legal capacity and power considerations - is that underdevelopment is at the root of the problem. But while underdevelopment is the primal 
force behind all three explanations, different policy prescriptions seem to follow from the explanations. If limited participation is explained by legal capacity, or to some extent power considerations, there is a problem with the way in which the WTO DS system works, and efforts may be justified to remedy this. Indeed, the Advisory Center on WTO Law is motivated by the perceived effects of lack of legal capacity on behalf of developing countries. On the other hand, if the use of the system mainly reflects trade structure (i.e. low gross volumes), there is less of a need to change the current DS system. A crucial question thus seems to be whether developing country participation in the DS system as complainants mainly reflects these countries' trade structures or more directly their developing country status.

The purposes of this study are two-fold. One is to shed light on the empirical question concerning the determinants of developing country participation in the DS system. In doing this we offer a number of contributions vis-à-vis the current literature. The first is that we work with a dataset on dispute initiation that is significantly extended compared to what is employed in the current literature. Our data set contains all Requests for Consultations at the WTO from 1995 through the end of 2006 (i.e., the first full 12 years under the current DS system). This provides a much broader sample for identification of patterns than employed in most existing studies. The second contribution is that we examine the role of trade volumes in participation rates across broad industry sectors. The current literature generally focuses on aggregate trade volumes. Our focus on sector patterns lets us further deconstruct the composition of trade as a potential explanation of developing country participation rates. Finally, we attempt to directly confront the problems caused by the dominance of zeros in the data set (i.e., the dominance of country-product pairs without observed disputes within the DS system). The second purpose of the study is to highlight a number of fundamental conceptual and data problems that beset the whole empirical literature that seeks to draw some form of policy conclusions based on participation in the DS system. While perhaps appreciated by researchers working in this area, these problems appear to go unnoticed by practitioners drawing on this literature.

The paper is structured as follows. In Section 2 we provide an overview of the literature on the determinants of participation in the DS system. In Section 3 we develop our analytical framework for explaining participation rates. Section 4 introduces the data that will be used to highlight the validity of the analytical framework. This is followed in Section 5 by 
an informal view on the data. Section 6 provides a formal (econometric) analysis of our data. Finally, in Section 7, we discuss our results and draw broader conclusions from the evidence.

\section{Background}

In this section we review the literature on the determinants of participation as complainants in the DS system. This review will be in two parts. We first point to a number of fundamental conceptual problems facing the literature. We then discuss more directly the literature. But since it is by now fairly sizeable, we will here only briefly point to a few studies that are of more direct relevance to the present study. ${ }^{1}$

\subsection{Conceptual issues}

As mentioned above, there are a number of very serious conceptual problems facing the literature on developing country participation in the DS system. We will here point to some of them.

\subsubsection{What is “a” dispute?}

In order to analyze the degree of participation in the DS system, it is necessary to be able to count the number of disputes. This in turn requires a definition of the unit of account of a dispute. A fundamental conceptual problem faced by the entire literature is that of choosing the unit of account for disputes. That is, what is "a" dispute?

From a data point of view, the simplest approach is to count each Request for Consultation as a separate dispute. Each such request is assigned a DS number by the WTO Secretariat, and there were 351 such disputes through December 2006. This is the approach taken in most of the more legally oriented literature that has sought to quantify participation in the DS system.

Another possibility, followed in the more economics or political science related literature, is to identify bilateral disputes. On this view, each complainant (sometimes there is more than one complainant), is counted as having a dispute with the respondent. The

\footnotetext{
${ }^{1}$ See Busch and Reinhardt (2002), or Horn and Mavroidis (2007), for a fuller account of the literature.
} 
consequence of this is to increase considerably the total number of disputes. For instance, with this approach the Bananas dispute DS27 would count as five bilateral disputes, since in this case five countries complained.

But there are also other aspects that could be taken account of. For instance, a large number of countries request to join consultations. It is not entirely clear whether these countries join because their interests coincide with those of the original complainant(s) or respondent, but it seems plausible that in most actual disputes, the joining countries have been on the side of the complainant(s). Also, even though not so frequent, sometimes essentially the same dispute appears under different DS numbers. Should they be viewed as the same or different disputes? There is furthermore also the question of how to view the way in which issues are "packaged” under a single DS number. If a complaint concerns two different measures affecting a particular product, is this to be viewed as two separate disputes which are just for convenience attacked in one complaint?

It should be emphasized that there is no generally correct way of defining a dispute. What is important however is that the definition employed corresponds to the question asked. That is, the definition should be derived from an underlying theory. We are not aware of any such attempts to date, however. There is thus a huge conceptual void in the middle of the whole discussion concerning developing country participation in the DS system.

\subsubsection{What defines the non-biased situation?}

A second very serious issue for studies of biases in participation is how to define the nonbiased benchmark. Without such a benchmark, it is impossible to say whether developing countries are "under-represented" or not. At the same time, most of the policy discussion on participation seems to completely ignore the issue. Again, there is a need for better, and more explicitly worded, theory.

\subsubsection{Why are illegalities committed?}

A third question of great significance is why countries commit illegalities? It makes a significant difference to the evaluation of the DS system if illegalities are committed to defuse domestic political pressures, or to aggressively pursue national or interest group interests. In the former case, the illegalities may prevent measures that would seriously threaten the unlawfully acting country's ability to maintain its commitments. There are 
some attempts to address this issue in the theoretical literature, but there is very little empirical work on this issue, except for an interesting paper by Bown (2004b) who examines the determinants of countries' choices of whether to violate or adhere to GATT rules when making trade policy changes during rounds. ${ }^{2}$

\subsubsection{What do observed dispute represent?}

To date, there have been significantly less than 400 such disputes. At the same time countries have undertaken many millions of decisions with a trade impact, each of which is potentially the target of a complaint. A highly pertinent question is then what purpose these disputes achieve, and what can be learnt about the working of the system by looking at participation in the system? How do we explain the fact that these particular conflicts ended up as formal disputes at the WTO, while other conflicts did not? That is, what determines the selection of disputes that appear before the WTO? The registered disputes most likely differ from other trade conflicts. But how do they differ? About this we know almost nothing.

\subsubsection{How do we interpret differences in participation?}

A central issue is clearly how to interpret the observation that a group of countries has launched few complaints. Perhaps the mere threat of complaints from this group sufficed to keep its trading partners at bay, partly due to the efficiency of the DS system. Or alternatively, perhaps one does not find it worthwhile to pursue disputes due to the poor functioning of the system. Or maybe certain countries are more fearful that if they complain, respondents will retaliate in some form. The same observation may thus lead us to completely different conclusions. We are not aware of any theoretical or empirical literature to guide us as to which is the better interpretation.

\subsection{The empirical literature on dispute initiation}

The literature on developing country participation in the DS system has focused on three sets of explanations. The first is that participation reflects commercial interests of countries. But the literature has also pointed to participation costs, legal capacity, and power politics as factors in the pattern of DS participation. According to the power hypothesis, developing countries abstain from launching disputes due to fear that they either will not be able to

\footnotetext{
${ }^{2}$ See Bown (2002), Bütler and Hauser (2000), Grinols and Perrelli (2003), and Guzman (2003).
} 
enforce rulings in their favor, or will be subjected to some form of revenge from more powerful countries if they do complain against them. In contrast, the legal capacity hypothesis holds that it is the limited ability of developing countries to detect illegalities and to litigate if illegalities are detected, given resource constraints, which puts developing countries at a disadvantage.

\subsubsection{Trade structure as a determinant of participation}

As noted above, a basic concern in the literature has been whether smaller and poorer WTO Members complain less often than they "should". Of course, it is highly likely that a country that exports many products to many markets and in large volumes will encounter more illegalities than a country that exports a few products in limited amounts to a few markets. The crucial question for determining any bias in the system is then how many more disputes the country with larger and more diversified exports should be involved in. Clearly, in order to address this issue, there is a need for a definition of an unbiased benchmark. Lacking any other plausible theory for the number of illegalities committed by each country, Horn et al (1999) assume that countries are equally prone to commit illegalities, in the sense that they do this with the same frequency for each imported product. Using data for the first four years of the WTO DS system, and with products defined at the 4-digit HS level, Horn et al (1999) show that the actual distribution of bilateral disputes across members are fairly well predicted by this benchmark, in particular when the latter is adjusted in order to exclude exports with smaller values (assuming that such values are not worth litigating over). This finding would thus suggest that the reason for the discrepancy between developed and developing countries in terms of complaints mainly reflects differences in trade interests.

Several studies have significantly improved on this study, often coming to rather different conclusions in the process. Notably, Bown (2005) argues that the assumption in Horn et al (2006) that illegalities are randomly and uniformly distributed across markets, products and trading partners, is strong. In particular, illegalities may be committed more frequently against weaker countries that do not have the capacity to retaliate. To get around this selection problem, Bown (2005) focuses on the choice of countries to either pursue disputes by themselves, participate as co-complainants or as third parties, or not participate at all, possibly free-riding on the efforts of other countries. To this end, the study employs an ordered probit model, applied to data for the period 1995-2001. The data builds on the 116 
disputes in which importing countries were determined to illegally restrict imports. Bown (2005) also identifies countries that were harmed by the illegal measure, but who did not participate in the legal process. It is shown that in disputes over measures that adversely affect many trading partners, the size of exports is positively related to the propensity to complain, in line with the finding of Horn et al (1999). It is also positively related to participation as a third party, and negatively related to the propensity to free ride.

\subsubsection{Legal capacity and "power" as determinants of participation}

Another important theme in the literature has been the role of limited legal capacity and limited economic "power” as restraints on developing country willingness to launch complains. The limited legal capacity of developing countries may prevent these countries from detecting illegalities, while their lack of “power” may make the enforcement of rulings to their favor difficult. It may also potentially result in retaliatory actions such as loss of preferential treatment status in trade (or more onerous rules of origin), or reduced foreign aid.

Horn et al use the size of countries' WTO delegations in Geneva as a proxy for countries' legal capacity and find that countries with more legal capacity litigate more, controlling for trade interests. However, this relationship is rather weak in their study. Dividing countries into four groups, G4, other OECD countries, developing countries other than LDCs, and LDCs, the study finds that developing countries other than LDCs are actually overrepresented as complainants against both G4 countries and against other OECD countries. On the other hand, LDCs seem to be underrepresented as complainants against developed countries, but this finding is uncertain due to the very small share of LDCs in world trade. Bown (2005) also uses the size of Geneva delegations as a proxy for legal capacity, but the variable is insignificant.

Another study on this theme is that of Guzman and Simmons (2005), who consider bilateral disputes in the WTO between 1995 and April 2004, as defined by Requests for Consultations. In addition to the commonly employed variable capturing the size of countries' Geneva delegations, Guzman and Simmons (2005) include the number of embassies abroad, countries' non-military government expenditures, and an index for the quality of government bureaucracies. Overall, Guzman and Simmons (2005) see their results as supporting the primacy of the legal capacity rather than power as an explanation 
of the choice of respondents. Because of legal resource constraints, developing countries are more selective as to which cases they challenge before the WTO.

The notion of "power” mentioned above is of course extremely vague, and could encompass a large number of aspects. As a measure of bilateral power relations, Horn et al (1999) use differences in GDP levels, but find little support for such a notion of power to matter. Bown (2005) uses two alternative measures of power. One of these is the trade retaliation capacity as proxied by fraction of the exporter's exports that goes to the importer. The estimated coefficient is positive, as expected, and significant.

One more specific aspect of power in international relations is the possibility for either party to withdraw foreign aid if faced by undesirable behavior by the other party. The role of aid for participation as complainants has been highlighted in a couple of studies. Bown (2005) includes bilateral aid in both directions. Bown (2005) argues that the more reliant an importing country is on the exporting country for development assistance, the more aid the exporting country could threaten to withdraw, and thus the more likely that the respondent would implement market-access commitments. However, Bown also notes that the respondent's reliance on aid from the exporter could indicate a special relationship between the two countries that might decrease the likelihood of complaints. The importer's bilateral aid dependence is measured by the aid received by the importer from the exporter as a fraction of the importer's national income. This variable is shown to be significantly negative, partly in contradiction with a power hypothesis.

Bown (2005) also examines the impact of the exporter's bilateral aid dependence. The coefficient for this variable, which is measured symmetrically, is shown to be significantly negative, as a power-based theory would predict. Hence, bilateral aid dependence reduces dispute participation, regardless of the direction of the aid.

A second study that illuminates the role of aid is undertaken by Zejan and Bartels (2006). ${ }^{3}$ They examine two aspects of aid dependence. The specification of direct relevance to the present paper is one where the probability of country $i$ launching a dispute against $j$ is

\footnotetext{
${ }^{3}$ While not addressing the same issue as is at stake here, it can be noted that Besson and Mehdi (2004) also highlight the role of aid, when examining determinants of whether developing countries win disputes. Basing their study on a sample of 40 disputes, and estimating a binomial probit model, they find among other things that dependence on bilateral foreign aid reduces the probability of winning a dispute against the donor.
} 
higher the less aid i received from $j$, the higher the GDP of $i$, the more trade dependent is $i$ and the larger is its legal capacity. ${ }^{4}$ The data employed covers the years 1995-2001 and concerns trade between developing countries and the EU and the US, respectively. When using probit regressions to estimate the model for both the EU and the US, the authors find some, albeit week, support for the proposition that developing countries complain less when they are more aid-dependent. When running separate estimations for the EU and the US, the relationship with the EU is found to be influenced by such considerations, but not that with the US. However, a closer statistical examination does not suggest any structural differences in the relationship between aid and dispute initiation when comparing the EU and the US. ${ }^{5}$

\subsubsection{Other factors explaining participation}

The literature contains several alternative factors as explanations for developing country complaints in the DS system. For instance, a frequent finding is that countries tend to complain less against members of the same preferential trade agreement to which they themselves belong. (As an example, see Bown 2005).

Another explanation is sought in the political systems of the potential complainants. Reinhardt (2000) examines a number of aspects of this issue, one being whether democracies are more or less likely to complain before the WTO. A number of theoretical arguments can be made in either direction, so while it seems plausible that the political system may affect the propensity to complain, the direction is unclear. Reinhardt finds however, that the more democratic a state is, the more it will initiate disputes, controlling for the trading countries' relative size, and for one country's dependence on trade with the other. There is also a strong tendency for democracies to be targeted more often. One possible explanation is that democratic governments find it harder to resist demands for protection, and will therefore be more prone to be pressured into committing illegalities. Reinhardt also finds that a country is more likely to initiate disputes against trading partners

\footnotetext{
${ }^{4}$ The other specification hypothesizes that the amount of aid received by a country $\mathrm{i}$ from a country $\mathrm{j}$ is lower, the larger the number of disputes that country i launch against country $j$, the lower the GDP per capita of $i$, and the less trade dependent $i$ is. This specification thus attempts to capture how aid is used to punish poorer countries that do use the DSB.

${ }^{5}$ This examination is performed using a likelihood ratio test, which effectively compares the log likelihood scores of from the two separate maximum likelihood estimations to see whether there is a significant difference in the relationship between aid dependence and dispute initiation for the and the US.
} 
that stand for large shares of the country's imports and exports, and also against countries that depend on it for their imports and exports, partly in line with what is found by Bown.

Yet another factor potentially affecting the propensity to initiate disputes is previous targeting for complaints. To capture such considerations, Reinhardt (2000) includes a binary variable indicating whether in the previous year the respondent initiated a dispute against the complainant. It is indeed found that a dispute in the previous year very significantly increases the probability of a dispute in the opposite direction the year thereafter. Bown also discusses the role of retaliation in several papers, finding support for its deterrent impact. (See Bown 2002, 2004a, 2004b). Yet another study with similar findings is that by Blonigen and Bown (2003), who employ disaggregated data from antidumping investigations

\section{Analytical framework}

We are interested in the reasons why countries take trade conflicts to the WTO DS system for adjudication. Our motivation is the question of whether there is some "bias" in the extent to which countries use the system. In particular, we want to explore the extent to which trade structure can explain the number of disputes that developing countries launch, controlling for other factors associated with underdevelopment.

As noted above, a generic problem for the whole literature on the use of the DS system is arbitrariness in the definition of the unit of account of a conflict. As we see it, a Request for Consultations in the DS system could be seen as a "package” of conflicts in several dimensions. For instance, the same request typically mentions a number of legal provisions that are allegedly being violated, often indicating that what is called a "measure" in reality consists of a number of different decisions; Hoekman, Horn and Mavroidis (2007) provide some descriptive statistics regarding this aspect of the DS system.

In this study we unravel this packaging across two dimensions. Specifically, we treat Requests for Consultations as aggregating trade conflicts in two dimensions: over complainants, and over products. Before studying the determinants of dispute initiation, we need to "unpack" the data on DS disputes. To this end, we will assume, first, that each complainant participating in a request is involved in a bilateral dispute with the respondent 
(which always is a single country). Second, we will assume that each industry that is involved in a DS dispute represents a separate dispute.

Before engaging in formal empirical analysis, it is necessary to first specify a theoretical or analytical framework spelling out how various factors may influence dispute initiation. We do this for two reasons. This first is simply that it ensures some rigor when we examine the data. In particular we will be able to refute the theory if the data turn out to tell another story than the theory we spell out here. Another reason to formalizing these relationships is that it allows us to show that the kind of implicit theory underlying the claims in much of the DS literature is much more elaborate, and special, than acknowledged.

Our framework, which will be concerned with litigation concerning import-restricting measures at an industry level, builds on a number of relationships. At a very general level, we stipulate that the number of complaints that an exporting country (indexed by i) has against an importing country (indexed by j), is larger:

(i) the larger the number of illegalities that country i detects that are committed by $\mathrm{j}$ against $\mathrm{i}$; and

(ii) the larger the gains from pursuing a dispute when an illegality is identified.

We do not know how to measure directly either of these entities, and for this reason we need to go behind each of them, disentangling them into factors that are more readily measurable. We start by assuming that the number of illegalities that country i detects that are committed by j:

(i) increase with the number of illegalities that are committed; and

(ii) increase with the probability of detecting a typical illegality.

We observe neither of these entities, of course. It is here natural to follow the literature and assume that more realized exports are likely to impose a stronger pressure on local producers, all else given, and that one would for this reason expect a positive relationship between exports and the number of committed illegalities. But it could also be argued that a low export volume may signal that many illegalities are committed. On this view, there would be a negative relation between export values and number of committed illegalities 
when we control for other factors. Our intuition suggests that the former factor normally dominates in the data. However, if we are to see a significant negative relationship, we at least have a plausible explanation.

We next turn to the probability that exporter i detects a committed illegality in j. In general terms, it seems reasonable to suppose that, for a given level of exports, the probability of detection increases in the legal capacity of the exporting country i. In the literature, it is in this context explicitly referred to as the capacity of official bodies, such as trade ministries, to detect illegalities. Of course, in practice the capacity of the private sector may be at least as important. We are touching here on a highly complex and under-researched area - the political economy of dispute initiation, and for practical purposes we need to stay with the simplistic description employed here.

Let us now turn to the gain for country $\mathrm{i}$ from launching a dispute against $\mathrm{j}$. We assume that it is influenced by three factors:

(i) the probability that country $\mathrm{i}$ wins against $\mathrm{j}$ if an illegality is detected and litigated

(ii) the direct gain for country $i$ if it wins in litigation against $j$

(iii) the expected retaliation by $\mathrm{j}$

Again, we need to go behind each of these factors in order to specify a theory that can be confronted with data. To this end, we take it that (i) the probability that country i wins against $\mathrm{j}$ if an illegality is detected and litigated increases in the legal capacity of exporter $\mathrm{i}$, and decreases in the legal capacity of importer $\mathrm{j}$.

We also assume that (ii) the direct gain for country $i$ if winning in litigation against $\mathrm{j}$ is larger the surplus from trade that is at stake (export value will be used as a proxy), and the better are the enforcement possibilities. The latter is assumed to increase in own national income and fall in that of the other country.

Finally, (iii) the expected retaliation by $\mathrm{j}$ is smaller the lower the potential cost of retaliation by importer $\mathrm{j}$ against exporter $\mathrm{i}$. There are of course many forms that such retaliation could take. The literature has pointed to the tendency for retaliation in complaints, whereby a complaint by i against $\mathrm{j}$ is met by a complaint in the opposite direction. We will here focus 
in particular on the developed-developing country dimension, and account for the possibility of withdrawal of aid as a disincentive for aid-receiving exporting countries to complain formally. ${ }^{6}$

The model described thus far does not have any explicit industry dimension. However, there are at least two ways in which the industry structure may enter the picture. First, the forces we have just described are likely to differ in strength across industries. Since countries differ in industry structure, they are for this reason likely to differ in their propensity to initiate disputes. Second, it seems intuitively plausible that the degree of conflict differs across consultation requests. Certain requests concern only a very specific issue, hitting only a narrow range of the potential trade between two countries, while other complaints concern measures that are much wider in their effects. To capture some aspect of this difference, we will define our disputes on an industry level (we will below describe exactly how this is done).

The model laid out above can thus be summarized as follows: The number of complaints by exporting country i against importing country j in industry g $\left(D I S P_{i j g}\right)$ is higher: ${ }^{8}$

- the greater exports of country i to country j in industry g $\left(X_{i j g}\right)$;

- the less the aid that $\mathrm{j}$ donates to $\mathrm{i}$, as a share of i's national income $\left(\frac{A I D_{j i}}{Y_{i}}\right)$;

- $\quad$ the greater the legal capacity of exporter i $\left(L_{i}\right)$;

- $\quad$ the less the legal capacity of importer $\mathrm{j}\left(L_{j}\right)$;

- the greater the national income of exporter i $\left(Y_{i}\right)$; and

\footnotetext{
${ }^{6}$ It would also be natural to include the withdrawal of preferential tariff treatment. However, as with preferential trading agreement, one would have to consider very carefully the real preference margin when taking account of rules of origin requirements, and the costs of verifying these. This requires a study on its own. (See e.g. Francois, Hoekman, and Manchin (2006) for such an attempt.)

${ }^{7}$ Another alternative is the power measure used by Bown (2005), discussed on page 10, which is the fraction of the exporter's export that goes to the importer. This can be used as a proxy for the importer's capacity for trade retaliation. However, since in our model this fraction also captures the probability that an illegality is committed, such a measure would be difficult to interpret.

${ }^{8}$ It could be hypothesized to be lower if the two countries are members of the same preferential trading agreement. However, these agreements vary hugely in terms of what they in practice entail. A satisfactory inclusion of a preferential trading agreement variable would therefore require a careful examination of the actual content of each bilateral match of countries with regard to preferential trading agreement that is far beyond the scope of the paper.
} 
- the less the national income of importer $\mathrm{j}\left(Y_{j}\right)$.

Note on the last variable that there are clearly factors that work in opposite direction to what we discuss above. For example, higher income countries may pose a greater benefit from improved market access (pointing to a positive coefficient), while the probability of winning may also be reduced (pointing to a negative coefficient). It is also conceivable that it is easier to find co-complainants for larger markets.

While this specifies the explanatory variables we build on, and the direction in which they are expected to influence dispute initiation, the theory is still silent on specifically how the various factors enter - what type of mathematical relationship they stand in. To make the model amendable to statistical analysis we could impose more specific assumptions to describe how these variables are assumed to be interrelated. Needless to say, there are many theoretical specifications that could seem reasonable here, and it is not clear how to choose among these. Since this inevitably arbitrary choice of functional form may importantly affect the outcome of the investigation, the standard approach in the literature is to abstain from such a specification, and to let the variables enter in an additive fashion. However, unfortunately this approach does not solve the problem with arbitrariness, since also an additive representation is implicitly based on specific assumptions concerning the relationships between the variables. In this study we will use a different formulation than the standard additive model, for reasons to be explained below.

We believe that the theory laid out above is about as plausible as any other presented in the literature. But as is obvious from the discussion above, even a simple formulation where dispute initiation is partly determined by trade structure, partly by legal capacity and partly by power considerations, becomes very elaborate on closer examination.

\section{Data}

We turn next to our data. It is convenient to first describe our explanatory variables (trade flows, national incomes, aid flows, and legal capacity), before describing how we construct the variable to be explained - dispute initiation.

\subsection{Country definitions}


A couple of comments regarding the countries included in the data set. First, throughout the study, we will let "EC" denote EU-15, the members of the EU before the enlargement in May 2004. We will treat the few DS disputes where EU-15 countries have been quoted as respondents, as complaints against the EC.

Second, as will be discussed below, there is a problem with data availability with regard to certain countries. For two WTO Members we lack data completely - Chinese Taipei (Taiwan), and Liechtenstein - and these are omitted from the study. The latter has not been involved in any disputes at all, but the former has been complainant in 8 disputes.

Third, for certain issues we divide the WTO Members into broader groups, working with the seven groups listed in Table 1.

Table 1: Country classification

\begin{tabular}{|l|l|}
\hline G2: & EC, US \\
\hline EI: & $\begin{array}{l}\text { Earlier Industrialized (non-G2 countries traditionally considered as } \\
\text { industrialized) }\end{array}$ \\
\hline NI: & Newly Industrialized \\
\hline HID: & $\begin{array}{l}\text { High Income Developing (exclusive of NIs), with GDP/cap }>\$ 4000 \text { according } \\
\text { to UNCTAD }\end{array}$ \\
\hline MID: & $\begin{array}{l}\text { Medium Income Developing, with } \$ 800<\text { GDP/cap }<\$ 4000 \text { according to } \\
\text { UNCTAD }\end{array}$ \\
\hline LID: & $\begin{array}{l}\text { Low Income Developing (excluding. LDCs), with GDP/cap }<\$ 800 \text { according } \\
\text { to UNCTAD }\end{array}$ \\
\hline CT: & Centrally planned or in Transition \\
\hline LDC: & 50 countries according to UN classification \\
\hline
\end{tabular}

The criteria mentioned in Table 1 are to be seen as indicative. The exact classification is given in Table 2. The general idea here is to distinguish between groups of countries that we believe might differ in a systematic fashion from each other, with regard to their incentives to initiate disputes. Most of the distinctions are hopefully fairly obvious, though like all classifications they can also be seen as somewhat arbitrary. The distinction between Newly Industrialized and High Income Developing countries is made to capture the 
Table 2: Country classification

\begin{tabular}{|c|c|c|c|}
\hline G2 & NI & HID & CT \\
\hline $\mathrm{EC}$ & Argentina & Antigua and Barbuda & Albania \\
\hline \multirow[t]{2}{*}{ US } & Hong Kong - China & Bahrain & Bulgaria \\
\hline & Israel & Barbados & China \\
\hline EI & Korea & Brazil & Croatia \\
\hline Australia & Malaysia & Brunei Darussalam & Czech Republic \\
\hline Canada & Mexico & Chile & Estonia \\
\hline Iceland & Philippines & Cyprus & Georgia \\
\hline Japan & Singapore & Gabon & Hungary \\
\hline Malta & South Africa & Kuwait & Kyrgyz Rep \\
\hline New Zealand & Thailand & Macao - China & Latvia \\
\hline Norway & Turkey & Oman & Lithuania \\
\hline \multirow[t]{2}{*}{ Switzerland } & & Qatar & Moldova \\
\hline & MID & Saint Kitts and Nevis & Mongolia \\
\hline LDC & Belize & Saudi Arabia & Poland \\
\hline Angola & Bolivia & Trinidad and Tobago & Romania \\
\hline Bangladesh & Botswana & United Arab Emirates & Slovak Republic \\
\hline Benin & Colombia & Uruguay & Slovenia \\
\hline Burundi & Congo & & \\
\hline Cambodia & Costa Rica & LID & \\
\hline Central African Rep & Cuba & Armenia & \\
\hline Chad & Dominica & Burkina Faso & \\
\hline Dem. Rep. Congo & Dominican Republic & Cameroon & \\
\hline Djibouti & Ecuador & Côte d'Ivoire & \\
\hline Gambia & Egypt & Ghana & \\
\hline Guinea & El Salvador & Guyana & \\
\hline Guinea-Bissau & Fiji & Honduras & \\
\hline Haiti & FYROM-Macedonia & India & \\
\hline Lesotho & Grenada & Kenya & \\
\hline Madagascar & Guatemala & Nicaragua & \\
\hline Malawi & Indonesia & Nigeria & \\
\hline Maldives & Jamaica & Pakistan & \\
\hline Mali & Jordan & Sri Lanka & \\
\hline Mauritania & Mauritius & Tanzania & \\
\hline Mozambique & Morocco & Zimbabwe & \\
\hline Myanmar & Namibia & & \\
\hline Nepal & Panama & & \\
\hline Niger & Papua New Guinea & & \\
\hline Rwanda & Paraguay & & \\
\hline Senegal & Peru & & \\
\hline Sierra Leone & Saint Lucia & & \\
\hline Solomon Islands & Saint Vincent \& the & enadines & \\
\hline Togo & Suriname & & \\
\hline Uganda & Swaziland & & \\
\hline Zambia & Tunisia & & \\
\hline & Venezuela & & \\
\hline
\end{tabular}


significant difference in e.g. technical sophistication of the industries of countries in the respective groups.

\subsection{Trade, aid, and income data}

With regard to the explanatory variables, in order to reduce the influence of missing values and of various stochastic shocks, we compute for each variable except for the dispute variable, a yearly average for the years 1998-2002 as long as data so permits. For the few instances where data have only been available for a subset of this period, we have computed averages for the available period.

Trade data are taken from COMTRADE. They nominally describe bilateral trade flows between all WTO Members at the 2-digit HS level. A significant fraction of data are missing - for the years 1998-2002 approximately $45 \%$ are missing, and we have to make adjustments in response to this significant lack of data. First, for some country combinations, we only have data for some years. In such cases, we then compute averages using whatever data are available for this period. Second, the COMTRADE data set only contains non-zero values, so there is of course a strong suspicion that whenever a number is missing, that there is no trade. ${ }^{9}$ On the other hand, for certain countries, such as Pakistan or Taiwan, it is clear that there is trade with a number of countries, despite the fact that no trade is reported.

In order to account for these problems, we assume, first, that whenever a value is reported for total imports for a country j from a country i (in which case also a HS number is always reported), that for those HS 2-digit industries for which no imports are reported, imports are zero. The sum of all HS 2-digit imports equals in such cases total imports, due to the existence of a unspecified category HS 99. Second, in cases where there is no information at all concerning the imports from i to $\mathrm{j}$, we omit the observation of this bilateral trade relation from the data set. ${ }^{10} 11$

\footnotetext{
${ }^{9}$ See Francois and Manchin (2007) on missing trade flows.

${ }^{10}$ To clarify, if imports by country j from country i are excluded, this is done for all HS categories. But such an exclusion does not mean that i cannot be recorded to import from j, nor does it affect i's or j's imports from other countries.

${ }^{11}$ The loss of data due to the lack of HS specification is relatively small, and in no instance exceeds $8 \%$ of total trade reported trade.
} 
With 132 WTO Members in the data set there are 132 x $131=17,292$ different bilateral pairs of import relations. With 15 different groups of industries, the total number of distinguishable bilateral import relations is 15 x $17292=259,380$. This is the number of records that our data set would include, if it were complete (excluding the two countries for which there are no data at all). However, due to the missing information, and the procedures described above meant to tackle this lacunae of information, the total number of records in our data set is 192,720.

Table A-1 in the Annex provides more detailed information on our data for trade structure, showing how each country's trade is distributed across our 15 industry groups.

Data on bilateral aid flows are taken from the OECD data base DAC Online, under the heading “2a Official Development Assistance”. It is here expressed in terms of constant year 2005 \$US. ${ }^{12}$

Finally, data on GDP at constant 1990 US dollars are taken from the UN Statistics Division $^{13}$, and these numbers are converted into constant 2005 \$US.

\subsection{Legal capacity}

It is very common in studies such as the present one to include some measure of legal capacity. Unfortunately, there are no direct measures of legal capacity, so instead some form of proxy variable has to be used. Before presenting the proxy employed here, let us make a couple of more general comments.

First, the literature has often used national per capita income as a proxy for legal capacity. This is natural, but problematic. For instance, certain countries have a highly educated elite, with excellent knowledge of WTO law, while at the same time having very low per capita income. India is an obvious example.

Second, another common proxy is the size of countries' WTO delegations in Geneva. This measure is employed e,g, by Horn et al (1999). There are problems with this proxy for legal capacity as well. For instance, while WTO delegates can be seen as experts on WTO issues,

\footnotetext{
${ }^{12}$ The data also contains some negative numbers, indicating repayment of earlier received, but unused, aid.

${ }^{13}$ Data is available at http://millenniumindicators.un.org/unsd/snaama.
} 
they are typically not experts on legal matters concerning the WTO. In addition, the direction of causality, to the extent there is a correlation, is not clear. It may well be that countries have large delegations partly in order to handle the many disputes they invoke. That is, size of delegations is not necessarily exogenous to the number of complaints. We therefore believe that the size of Geneva delegations is a problematic measure of legal capacity. Instead we will use other measures that are more exogenous to the issue at stake here. These are discussed below.

Third, it should also be noted that in general, when using proxies for legal capacity that essentially measure the quality of the legal capacity, and not its available quantity, as an explanatory variable, it is important to take proper account of the dimensionality of the model. For instance, in our specification (as in most other similar attempts in the literature), we seek to explain the absolute number of disputes pursued between any pair of countries i and j, by (among other things) legal capacity variables $\left(L_{i}\right)$ and $\left(L_{j}\right)$. These latter variables should hence measure the absolute amount of legal capacity of the exporting and the importing country, respectively. Amorphous as this notion of legal capacity is, it seems plausible to be larger, all else given, the larger is the population and the higher is its level of education. Assuming that the level of education is proportional to national income per capita (denoted $Y C A P_{i}$ ), the following would be a simple specification to capture this relationship: $L_{i}=P O P_{i} \cdot Y C A P_{i}$. But, since $Y C A P_{i}=Y_{i} / P O P_{i}$, the aggregate amount of legal capacity would simply be proportional to the income of the country:

$$
L_{i}=P O P_{i} \frac{Y_{i}}{P O P_{i}}=Y_{i}
$$

That is, we should under this reasoning not use income per capita, but total income, as a proxy of the absolute amount of legal capacity of a country.

In this study we will use a proxy for the quality of legal capacity. The World Bank Worldwide Governance Research Indicators Dataset provides several such indices, as for instance those for Government Efficiency, Regulatory Quality, and Rule of Law. ${ }^{14}$ It seems likely that the general quality of the legal system, which of course could be measured in a

\footnotetext{
${ }^{14}$ Available at http://www.worldbank.org/wbi/governance/govdata.
} 
large number of ways, is positively correlated with each of these measures. The data are provided for the years 1998, 2000 and 2002, and we calculate simple averages of these three years for each Member. Not surprisingly, the three World Bank indices are highly correlated (the correlations are larger than .8). We have chosen to use the Government Efficiency index. In order to take account of the above-mentioned problem that this index does not measure the total amount of legal capacity, but its quality, we multiply the index by the logarithm of GDP to construct our legal capacity measure. ${ }^{15} 16$

The World Bank index provides numbers for the individual Members of the EU. In order to form an index value for the EC, we have weighted each country's value with the country's share of EU-15 GDP, for each year.

The resulting legal capacity index is provided in the Annex in Table A-2, in the column “Own legal capacity”.

\subsection{Dispute data}

Dispute data are taken from the Horn and Mavroidis WTO Dispute Settlement Data Set, originally compiled in a World Bank project. ${ }^{17}$ This data set has recently been updated to include all 351 WTO disputes - what we will denote "DS disputes" - initiated through the filing of a Request for Consultations at the WTO, from 1 January 1995 until December 31, 2006, and for these disputes it includes events occurring until this date. The data set covers exhaustively all stages of dispute settlement proceedings, from when consultations are being requested to the eventual implementation of the rulings. The data set contains several hundred variables, providing information on various aspects of the legal procedure. From this data set we will take information on the identity of the complainants and the respondents, and the Harmonized System classification of the products concerned.

\footnotetext{
${ }^{15}$ It could be though that the inclusion of the log of GDP both in this index, and directly, will produce problems of multicollinearity in the econometric analyses to follow. However, as will be seen, this is not actually a problem.

${ }^{16}$ More precisely, the index is constructed such that it takes both positive and negative values (the average index calculated for the three years 1998, 2000 and 2002 vary between approx -1.83 and 2.5). It is transformed as follows:

$$
L_{i}=\ln \left(Y_{i}\right) \cdot\left(G o v E f f_{i}+\operatorname{abs}\left(\min _{\forall k} G o v E f f_{k}\right)\right)
$$

${ }^{17}$ The data are available at the www.worldbank.org/trade. However, at the time of writing, the World Bank website does still not have the most recent version of this data set, which is what has been used for this study.
} 
We transform the data in several ways. First, the conceptual framework to be used in this study concerns import measures. We therefore want to omit from the data set all disputes concerning export measures. From an economic point of view, it is difficult to determine whether a measure amounts to export promotion only, or also restrict imports, due to the interrelationship between markets. For instance, a measure that at the face of it appears as only enhancing exports, may in practice act as an import restriction in other markets. There is therefore a considerable degree of arbitrariness in the decision concerning which DS disputes to omit from the data. We have chosen to omit those DS disputes where the matter stated in the consultation request mentions export subsidization, leaving 333 DS disputes in the data set. ${ }^{18}$ This procedure eliminates approximately $5 \%$ of the DS data.

Second, we want to define industry-specific disputes. The data set we draw on provides the HS number(s) that were mentioned in the Requests for Consultations. These data vary greatly in the number of products being mentioned and the HS level. For some disputes there is no specification at all of a HS number. This is sometimes due to the fact that the contested measure is of such a nature as to not apply to any specific product, but it can also reflect the fact that the complaint is not very specific. In contrast, for other disputes a very large number of HS numbers are provided, and sometimes at a very detailed level. To match our dispute data to trade data, we have to make changes to the data set in order to account for the fact that we do not have HS numbers for all disputes:

(i) We delete all DS disputes for which there is neither a HS number specified, nor a product description.

(ii) For those DS disputes where there is no HS number specified but a verbal product description is given, we try as far as possible to use these descriptions to classify the industry concerned, as long as they refer to one or several specific (2-digit) industries, and

\footnotetext{
${ }^{18}$ The following DS disputes were omitted on the basis of this criterion: $35,46,70,71,103,104,113,120$, $127,128,129,130,155,194,222,265,266$, and 276 . The decision to omit export subsidies is admittedly arbitrary. For instance, the Brazil-Canada aircraft disputes are omitted from the data due to this, but not the Boeing-Airbus disputes. Even though the latter disputes concern imports to a larger extent than the former, they still seem fairly similar in nature. However, once we start making more discretionary decisions, we risk introducing other forms of bias into the material.
} 
not more generic categories, (such as “manufactures”). In cases where both a HS 2-digit product is mentioned, and something more generic, we include only the former. ${ }^{19}$

(iii) In order to make the statistical analysis more practical, we aggregate the almost 100 HS 2-digit industries into broader groups of industries. Another reason for aggregating the industries is the fact that disputes seem to be HS-classified in very different ways. For instance, in textiles disputes many 2-digit industries are mentioned, while this is not as common for other products. There is unfortunately a significant amount of arbitrariness in any classification of this sort, while at the same time the the choice of classification may have importance for the empirical findings. ${ }^{20}$ We have chosen to identify 15 different groups of industries, as listed in Table 3. A more detailed description is provided in Table A-3. The basic idea is thus that these groups of industries should be disparate enough so that a DS dispute involving two of them can be seen as effectively packaging two separate disputes. Our classification largely overlaps with the division in the HS system of the HS 2digit industries into "sections".

\section{Table 3: Grouping of HS 2-digit industries}

HS-2 digit numbers

$1-24$

25-27, 68-70

28, 29, 31

30,33

32, 34-38

39,40

41-43, 64, 66, 67

44-48

50-63, 65

72,73

74-83

84,85

86-89

90-96

49, 71, 97
Notation Very broad description

Agr Agricultural prod.

Mt1 Materials 1

Ch1 Chemical prod. 1

Pha Pharmaceuticals

Ch2 Chemical prod. 2

Pla Plastics and rubber

Mt2 Materials 2

Woo Wood (incl articles)

Txl Textiles

Stl Iron and steel

Met Metals other than iron

Mch Machinery

Vhl Vehicles

Man Misc manufactures

Oth Other

\footnotetext{
${ }^{19}$ This eliminates the following DS disputes: 37, 45, 80, 82, 83, 115, 117, 124, 125, 160, 170, 176, 186, 196, 199, 201, 224, and 285.

${ }^{20}$ For instance, had we used instead a HS 4-digit level, there would have been many more disputes. However, it should be recalled that the same method is applied to all disputes, and that what matters to us is the relative distribution of the number of disputes.
} 
This procedure implies that there are 319 “industry-specific bilateral disputes” (ISBD) in our data, each of which concerning one complaining country, one responding country, and one of the 15 groups of industries. Table A-4 lists the DS disputes from which these are formed and Table A-5 gives the complainants, and the industry groups involved.

Finally, Table 4 contains summary statistics for the variables in the data set.

Table 4: Summary statistics

\begin{tabular}{|c|c|c|c|c|c|}
\hline & Obs & Mean & Std dev & Min & Max \\
\hline Disputes (i,j,g) & 192720 & 0.00 & 0.06 & 7.00 & 12.00 \\
\hline Legal cap exporter & 192720 & 45.89 & 23.91 & 0.00 & 109.74 \\
\hline Legal cap importer & 192720 & 48.27 & 22.88 & 12.11 & 109.74 \\
\hline $\ln (G D P$ exporter) & 192720 & 23.61 & 2.21 & 19.25 & 30.01 \\
\hline $\ln$ (GDP importer) & 192720 & 23.71 & 2.20 & 19.51 & 30.01 \\
\hline Aid dependence & 192720 & 0.02 & 0.25 & -0.20 & 10.68 \\
\hline $\ln ($ Agr $)$ & 192720 & 0.61 & 2.79 & 0 & 23.38 \\
\hline $\ln (\mathrm{Ch} 1)$ & 192720 & 0.35 & 2.09 & 0 & 23.68 \\
\hline $\ln (\mathrm{Ch} 2$ & 192720 & 0.36 & 2.05 & 0 & 22.54 \\
\hline $\ln ($ Man) & 192720 & 0.45 & 2.27 & 0 & 23.96 \\
\hline $\ln ($ Mch) & 192720 & 0.57 & 2.65 & 0 & 25.01 \\
\hline $\ln ($ Met $)$ & 192720 & 0.38 & 2.11 & 0 & 22.81 \\
\hline $\ln (\mathrm{Mt1})$ & 192720 & 0.45 & 2.38 & 0 & 24.07 \\
\hline $\ln (\mathrm{Mt} 2)$ & 192720 & 0.34 & 1.94 & 0 & 23.42 \\
\hline $\ln ($ Oth) & 192720 & 0.33 & 1.90 & 0 & 23.11 \\
\hline $\ln$ (Pha) & 192720 & 0.35 & 2.00 & 0 & 23.20 \\
\hline $\ln ($ Pla) & 192720 & 0.43 & 2.26 & 0 & 23.04 \\
\hline $\ln (\mathrm{Stl})$ & 192720 & 0.39 & 2.15 & 0 & 22.45 \\
\hline $\ln (T x l)$ & 192720 & 0.52 & 2.49 & 0 & 23.69 \\
\hline $\ln ($ Vhl) & 192720 & 0.39 & 2.16 & 0 & 24.80 \\
\hline $\ln (W o o)$ & 192720 & 0.41 & 2.18 & 0 & 23.85 \\
\hline exposure & 192720 & 10.04 & 2.81 & 1.06 & 12.00 \\
\hline
\end{tabular}

\section{General patterns in the data}

Given our data, we start with an overview of patterns in the distribution of disputes. This highlights that, as in the older data on which the earlier literature is based, we also observe a high correlation between indicators of size, development, export volumes, and participation in the DS process. A natural first step when approaching the question of the determinants of dispute initiation is to look at the extent to which it varies with certain 
factors that it intuitively is likely to be influence by. We therefore start by looking at what is to be explained - the pattern of dispute initiation.

We first plot in Figure 1 each country's share of all WTO Members' exports against the number of ISBD disputes the country has been involved in. As can be expected, and repeatedly pointed out in the literature, there is indeed a very strong positive correlation between the two. Figure 2 demonstrates another well-known relationship, by plotting the (log of) national income against the number of complaints. Clearly, larger countries initiate more disputes.

Figure 1: For each WTO Member, Member's share of total exports against the number of industry-specific bilateral disputes for Member

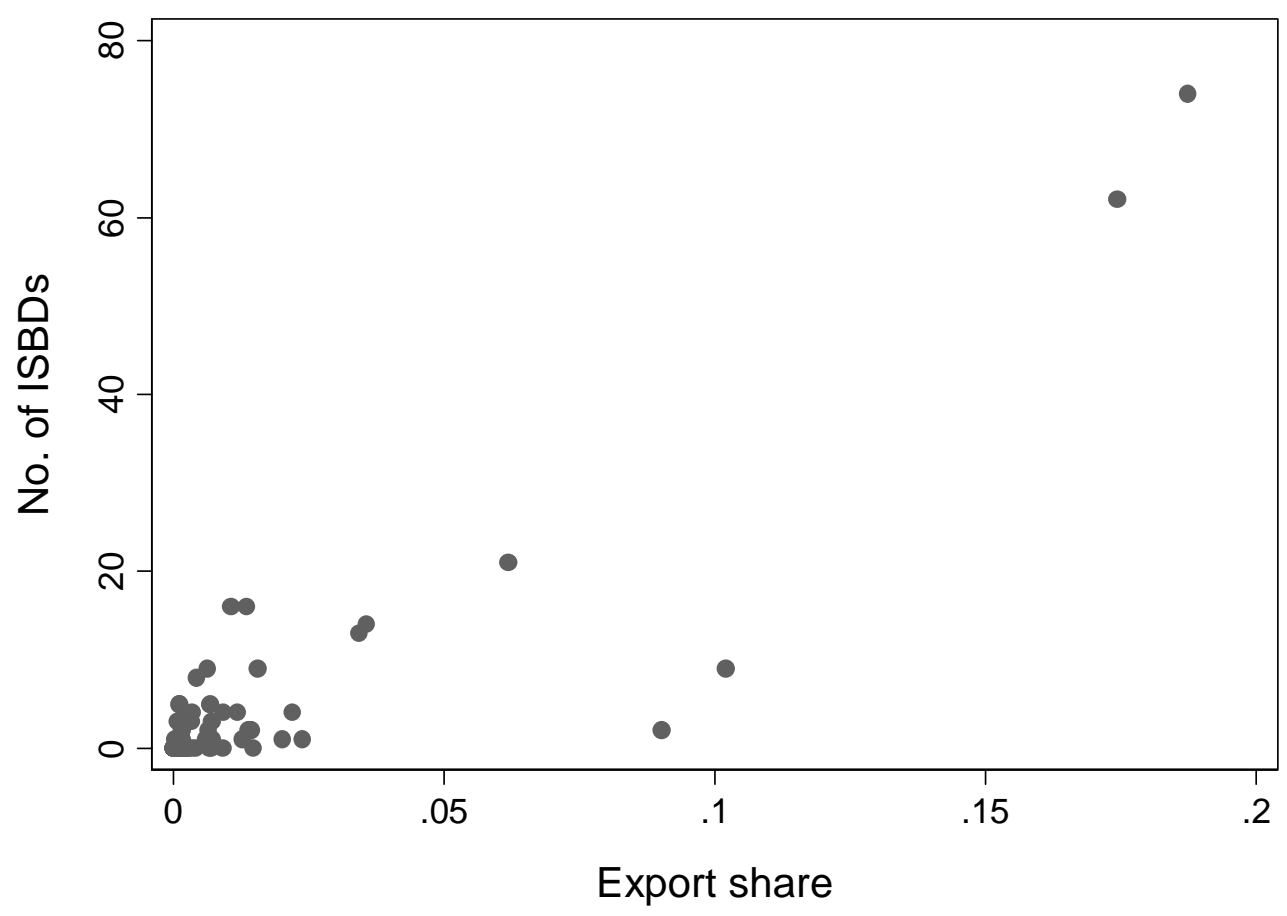


Figure 2: For each WTO Member, the logarithm of GDP against the number of industry-specific bilateral disputes for Member

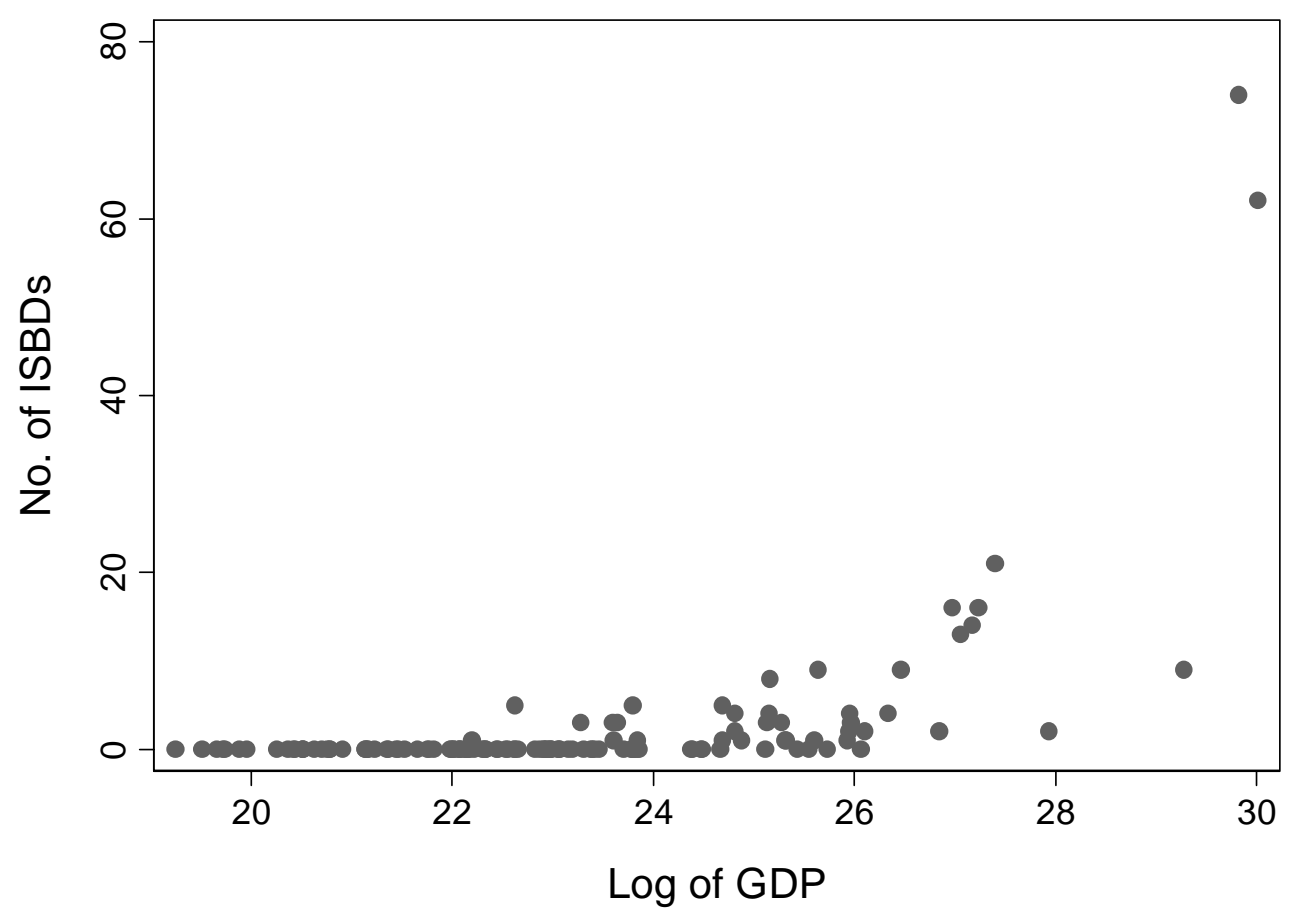

Figure 3 highlights the relationship between the legal capacity of each country and the number of ISBDs it has been involved in. Again, an expected pattern emerges, whereby countries with greater legal capacities are involved as complainants in more disputes. 
Figure 3: For each WTO Member, the Member's legal capacity against the number of industry-specific bilateral disputes for Member

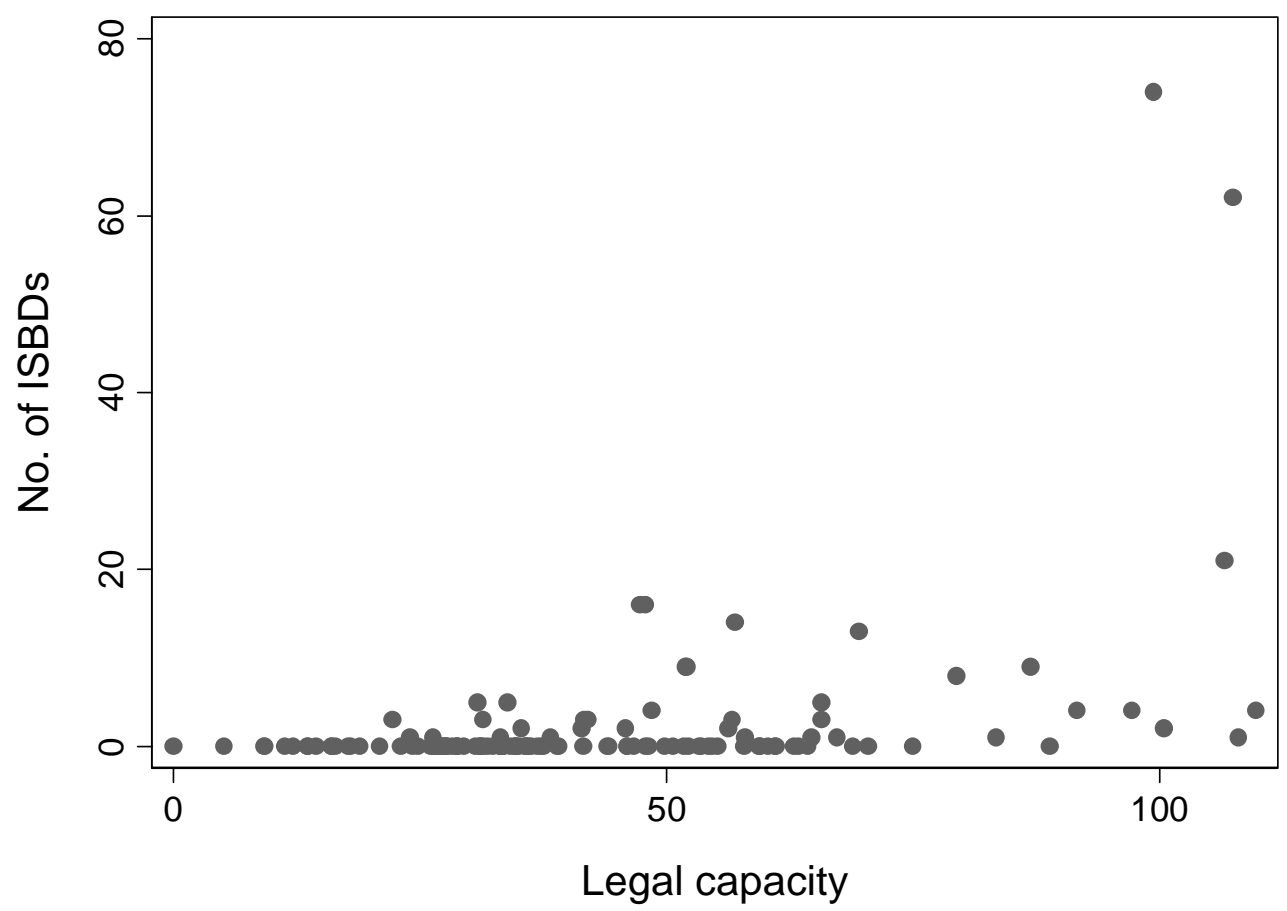

The relationship between aid flows and dispute initiation is summarized in Figure 4. It plots for each country i the aid received by i from all other WTO Members as a fraction of i's income, against the country's no of ISBDs. As can be seen, there is clearly a very strong negative correlation between the two entities: countries for which aid constitute a large fraction of national income typically initiate few or no disputes. (Note that this correlation does not mean causation.) 
Figure 4: For each WTO Member, the Member's net receipt of aid from other WTO Members as a fraction of Members GDP against the number of industry-specific bilateral disputes for Member, for positive net receipts

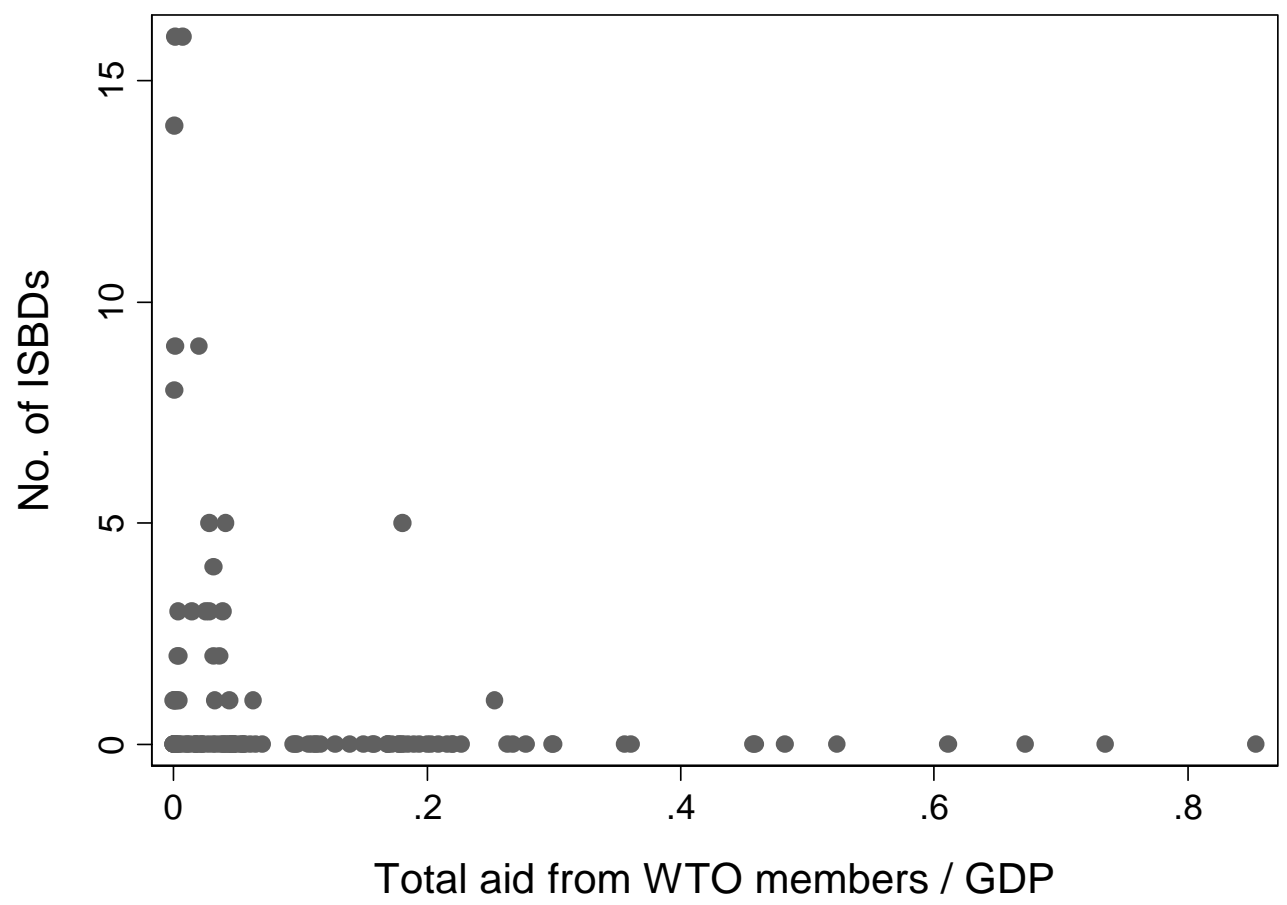

Let us next turn to the relationship between export structure, in the sense of the industries in which countries trade, and dispute initiation. It is natural to believe that certain industries are more likely to feature disputes than others, for instance because more concentrated industrial structures encourage more lobbying by industry. There are therefore reasons to believe that the difference between developed and developing countries in trade structure can explain at least part of the difference in dispute initiation across the two groups.

Figures 5 and 6 highlight the correlation between the export share of developing countries for the various HS 2-digit industries, and dispute initiation, in two slightly different ways. Figure 5 plots for each HS 2-digit industry, the developing country share of total exports in the industry on the horizontal axis, against these countries' share of the disputes involving this industry. The plot thus illustrates whether the industries in which developing countries have a large export share are those where they also have a large share of the disputes. There is (at least seemingly) not a very strong relationship between the two. 
Figure 5: For each HS 2-digit industry, developing country share of total exports in the industry against their share of the disputes involving this industry

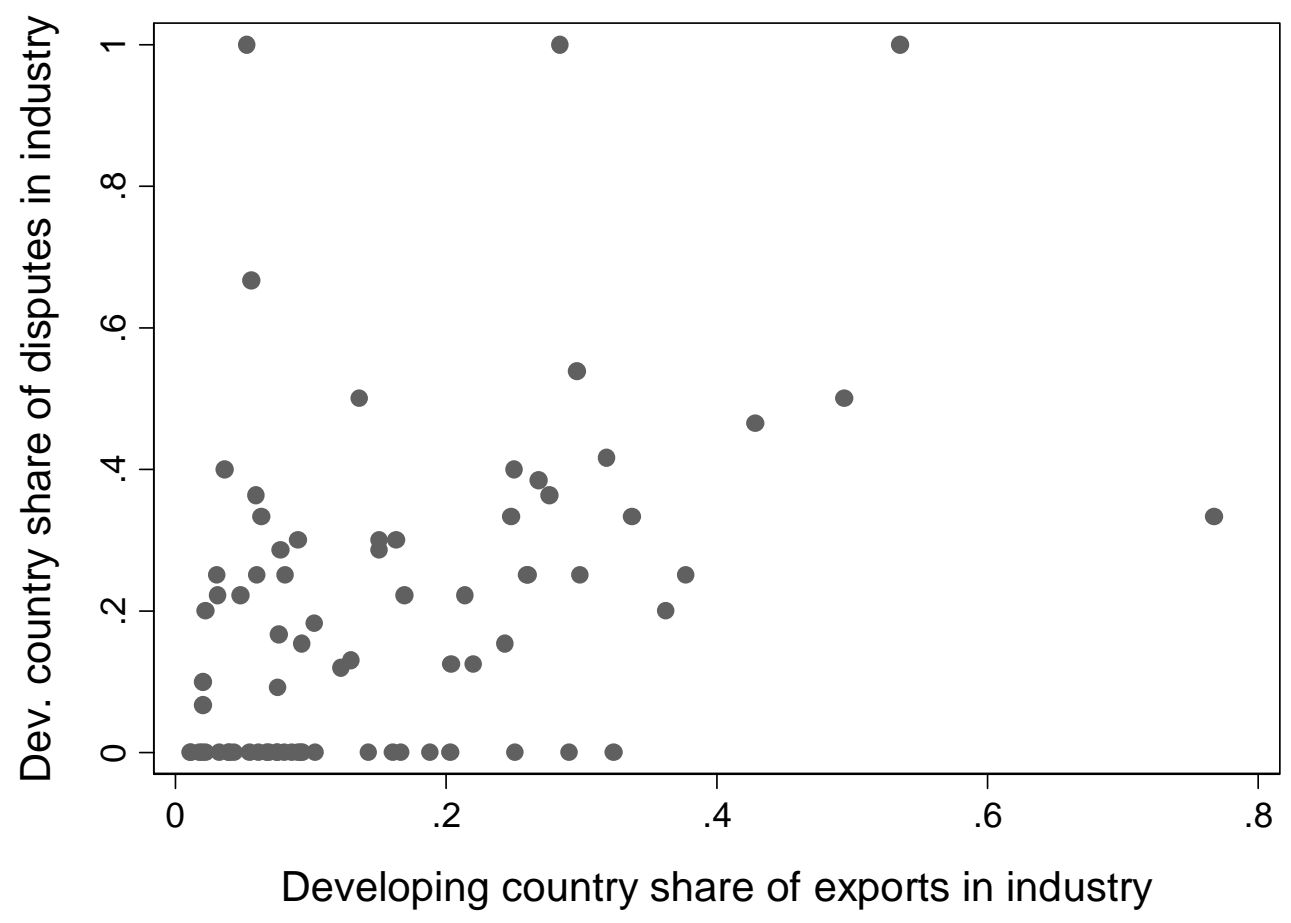

Figure 6 looks at the issue from a slightly different perspective. The horizontal axis is as in the previous figure, but now the share of exports for developing countries in each industry, is plotted against this industry's share of all disputes. This figure could thus be indicative of a situation where developing countries, relative to developed countries, export in industries where there is relatively little litigation. No such relationship can be discerned through this plot however. Hence, a superficial glance at the data suggests that any problem with developing country under-representation as complainants does not seem to be related to their export pattern across industries. 
Figure 6: For each HS 2-digit industry, developing country share of total exports in the industry against the industry share of all disputes

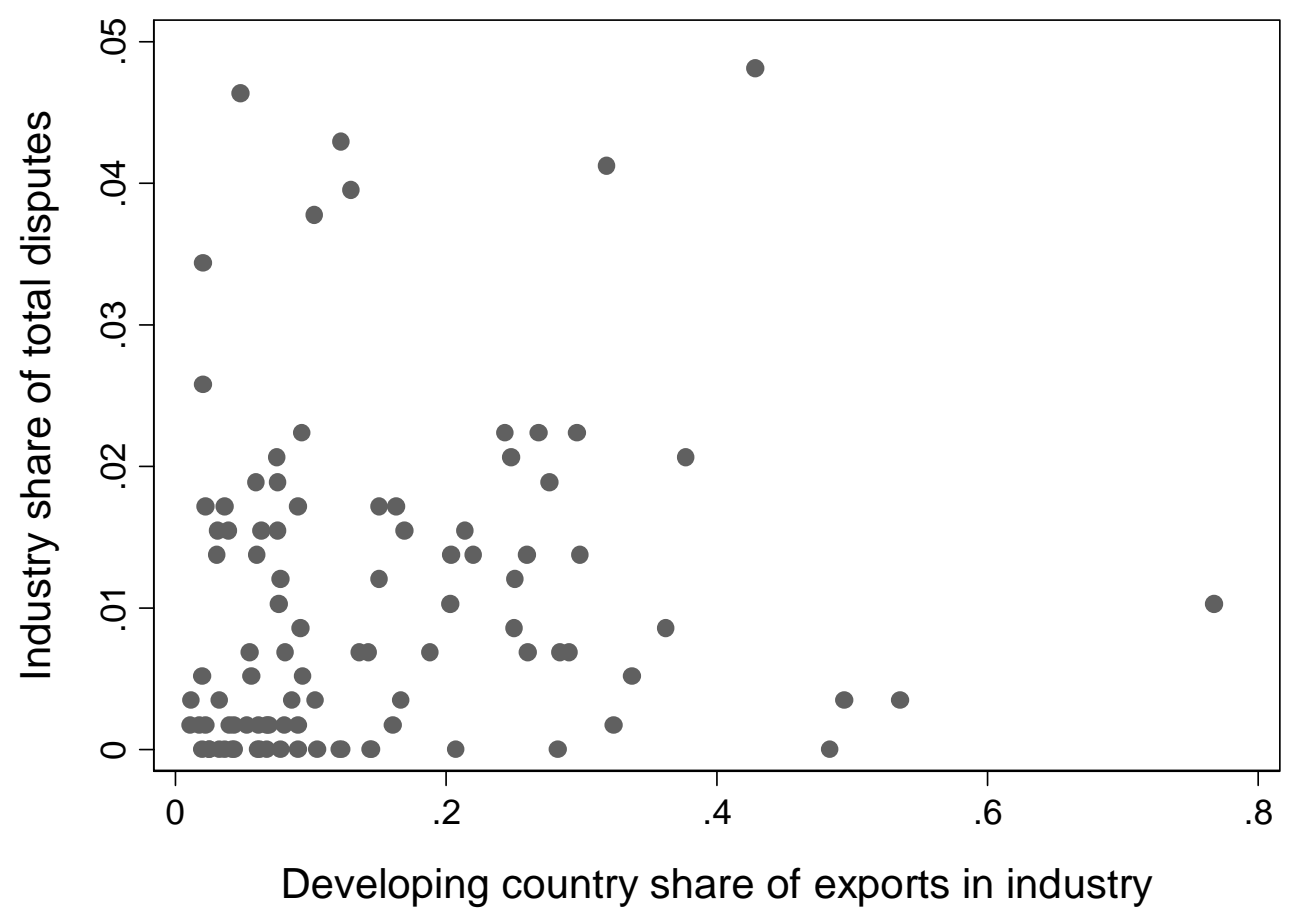

To conclude, it appears from the figures above as if dispute initiation is strongly positively correlated with trade values and with the size of GDP. It is also positively related to our measure of legal capacity, and negatively related to our measure capturing power considerations (aid dependence). But dispute initiation seems to vary less systematically with trade structure. We cannot stop the analysis here, however, for a number of reasons. First, the figures above say nothing about the direction of causality. Second, the lack of correlation between dispute initiation and trade structure does not necessarily imply that these are not interrelated when controlling for other factors. Third, even if dispute initiation is caused by the factors we have highlighted, the figures are not very informative with regard to the relative strength of the various factors. Furthermore, many of the factors we use to explain dispute initiation are just reflections of the same underlying factor, and they can all be said to reflect underdevelopment one way or the other. It would be clearly be desirable to disentangle the impact of the various factors, and to determine the relationship between them. To this end, we have to turn to econometric analysis.

\section{Econometric analysis}


An econometric analysis of the determinants of dispute initiation requires at least three components:

(i) a hypothesis - or theory - for the determinants of dispute initiation;

(ii) a set of data on the variables of relevance; and

(iii) a statistical method for examining the extent to which the data supports the hypothesis.

We have already specified component (i) - for a working hypothesis, we rely on the conceptual framework spelled out in Section 3 - and (ii) - the data needed to analyze this framework were described in Section 4. As we have seen, there are potentially serious conceptual problems involved in any the specification of the theory in this area, and in the construction of the variables to be used when testing.

We now turn to component (iii). As will be argued, it will be highly important to choose a statistical method that suits the peculiar features of the data at hand. There are here two broad types of purposes that the analysis may seek to fulfill. One purpose of the analysis is that it should be analytical, explaining relationships of interest. The aim is then to find causal, or at least significant, relations. The main requirement on the model is to include all relevant variables, and the explanatory variables have to be exogenous. The other purpose is descriptive, often with the hope of making prediction. The main requirement on the model is then that it has a good ability to predict. The present study can be said to combine elements of both these approaches, by emphasizing the desirability of estimating significant relationships, at the same time as using the model for predictions.

\subsection{The choice of statistical model}

A natural starting point when seeking to disentangle the relative influence of different factors is to use multiple ordinary least squares (OLS) regression analysis. The basic version of the OLS model posits a linear relationship between the dependent and the explanatory variables. However, a fundamental feature of dispute initiation data is that it is “count data” - it takes on only non-negative integer values $(0,1,2 \ldots$ etc.). In addition, there is a heavy dominance of zeros for the ISBD variables: for the 192,720 observations we have in the data, there are disputes observed in only approximately $0.1 \%$ of the instances. Hence, roughly $99.9 \%$ of the variable to be explained consists of zeros. As a 
result, when using the linear OLS model, the errors will not be normally distributed, and the model is consequently unsuitable.

Note that the dominance by zeros in the data set is not special to our data set, but is simply a reflection of the small number of disputes in the DS system relative to the number of potential complainant/respondent pairs. Even if one abstained from disaggregating disputes according to industry group, there would still be a heavy dominance by zeros. As can be seen, it requires special methods for the few disputes that are in the data set, not to "drown" in all the zeros in the estimations.

A very common attempted remedy to the problems caused by the skewed distribution of the dependent variable, which is a characteristic of count data, is to let the dependent variable (here the number of disputes) enter in logarithmic form, in order to make the distribution of the error term closer to the normal distribution. However, this would not suffice in the present case. Instead, there is a need to employ a statistical model that is designed to take account of the particular features of count data. A natural candidate here, which we will also adopt, is the negative binomial regression model. This model is in theory, and normally also in practice, much better suited to handle problems arising from count data than is the linear OLS model. ${ }^{21} 22$

The negative binomial model we will estimate has the following underlying specification:

$$
E\left(D I S P_{i j g} \mid z^{\prime} \beta, t\right)=t \cdot \exp \left(\beta_{0}+\sum_{g} \delta_{g} \beta_{1 g} \ln X_{i j g}+\beta_{2} L_{i}+\beta_{3} L_{j}+\beta_{4} \ln Y_{i}+\beta_{5} \ln Y_{j}+\beta_{6} \frac{A I D_{j i}}{Y_{i}}+\varepsilon_{i j g}\right)
$$

$t$ is the length of time both $\mathrm{i}$ and $\mathrm{j}$ have been members, and $\delta_{g}$ are dummies taking the value of one when the industry group concerned is g, and is otherwise equal to zero.

\footnotetext{
${ }^{21}$ See e.g. Cameron and Trivedi (1998) for an exposition on econometric methods for count data.

${ }^{22}$ The negative binomial model nests as a special case the Poisson count model. But it is on a priori grounds better suited than a standard Poisson model for the situation at hand, both since it is can better handle situations with many zeros, and since it can handle problems of over-dispersion (i.e., situations where the variance exceeds the conditional mean), both of which are inherent features of our data. Also, if there are problems with omitted variables (as in our case), that will translate to a larger error term, in effect resulting in over-dispersion. Our estimations will confirm the choice of the negative binomial model over the standard Poisson model.
} 
At risk of explaining the obvious, let us just say that the point of the estimation is to find values of the coefficients $\beta_{0}, \beta_{1, \text { Agr }}, \ldots, \beta_{1, \text { Woo }}, \beta_{2}, \ldots, \beta_{066}$ such that the model on the basis of the explanatory variables on the right-hand side of the equation, predict dispute initiation across triples of (exporter, importer, industry group) as closely as possible to actual dispute initiation (the variable on the left-hand side). Having determined these coefficients, and assuming we trust the values thus calculated, we would from the magnitude of these values know the influence of each of the explanatory variables.

\subsection{The estimated model}

Table 5 gives the results of the estimation of the negative binomial regression model.

\section{Table 5: Estimation of the negative binomial regression model}

Number of observations 192720 Log pseudolikelihood $=$ $-994.264$

Dispersion $=$ mean Prob $>$ chi $2=$

Wald chi2 $(20)=$ 1220.14

(Robust standard errors, adjusted for 132 clusters in comp)

Dependent variable: No of ISBD

exposure (exposure)

\begin{tabular}{|c|c|c|c|c|c|c|}
\hline \multirow[b]{2}{*}{ Legal cap exporter } & \multirow{2}{*}{$\begin{array}{c}\text { Coef. } \\
-0.01\end{array}$} & $\begin{array}{l}\text { Std. } \\
\text { Err. }\end{array}$ & & $\mathbf{P}>|\mathbf{z}|$ & \multicolumn{2}{|c|}{ [95\% Conf. Int.] } \\
\hline & & 0.00 & -1.45 & 0.15 & -0.01 & 0.00 \\
\hline Legal cap importer & -0.02 & 0.00 & -4.66 & 0.00 & -0.03 & -0.01 \\
\hline $\ln$ (GDP exporter) & 0.29 & 0.06 & 4.74 & 0.00 & 0.17 & 0.42 \\
\hline $\ln$ (GDP importer) & 0.55 & 0.07 & 8.06 & 0.00 & 0.41 & 0.68 \\
\hline Aid dependence & -3.28 & 1.21 & -2.71 & 0.01 & -5.66 & -0.90 \\
\hline $\ln ($ Agr $)$ & 0.60 & 0.05 & 12.38 & 0.00 & 0.51 & 0.70 \\
\hline $\ln (\mathrm{Ch} 1)$ & 0.49 & 0.05 & 8.83 & 0.00 & 0.38 & 0.59 \\
\hline $\ln (\mathrm{Ch} 2)$ & 0.48 & 0.06 & 8.71 & 0.00 & 0.38 & 0.59 \\
\hline $\ln ($ Man) & 0.40 & 0.06 & 6.69 & 0.00 & 0.28 & 0.52 \\
\hline $\ln ($ Mch $)$ & 0.48 & 0.05 & 10.41 & 0.00 & 0.39 & 0.57 \\
\hline $\ln ($ Met) & 0.42 & 0.06 & 6.63 & 0.00 & 0.30 & 0.54 \\
\hline $\ln (\mathrm{Mt1})$ & 0.47 & 0.05 & 9.44 & 0.00 & 0.38 & 0.57 \\
\hline $\ln (\mathrm{Mt} 2)$ & 0.53 & 0.05 & 11.26 & 0.00 & 0.44 & 0.62 \\
\hline $\ln ($ Oth) & 0.46 & 0.06 & 8.29 & 0.00 & 0.35 & 0.57 \\
\hline $\ln ($ Pha) & 0.52 & 0.05 & 9.53 & 0.00 & 0.41 & 0.63 \\
\hline $\ln (\mathrm{Pla})$ & 0.46 & 0.06 & 8.06 & 0.00 & 0.35 & 0.57 \\
\hline $\ln (\mathrm{Stl})$ & 0.55 & 0.05 & 10.72 & 0.00 & 0.45 & 0.65 \\
\hline $\ln (T x l)$ & 0.52 & 0.05 & 10.60 & 0.00 & 0.43 & 0.62 \\
\hline $\ln (\mathrm{Vhl})$ & 0.53 & 0.05 & 10.67 & 0.00 & 0.43 & 0.63 \\
\hline
\end{tabular}




$\begin{array}{lcccccc}\text { In(Woo) } & 0.51 & 0.05 & 9.35 & 0.00 & 0.40 & 0.62 \\ \text { _cons } & -36.80 & 2.33 & -15.79 & 0.00 & -41.36 & -32.23 \\ \text { exposure } & \text { (exposure) } & & & & & \\ & & & & & & \\ \text { /nalpha } & 0.85 & 0.33 & & & 0.21 & 1.49 \\ \text { alpha } & 2.34 & 0.76 & & & 1.24 & 4.43\end{array}$

Let us first note that the legal capacity of the exporter is the only coefficient that is insignificant - all other parameters are significant at the 1\% level (or better). The coefficient for legal capacity of the importing country is significant however, and negative as the theory predicted: higher-capacity importers tend to face fewer disputes. This part of the "legal capacity hypothesis" discussed in Section 2 is thus confirmed.

As always in these instances, it is hard without much further examination to determine the reason why the legal capacity of the exporting country is insignificant. ${ }^{23}$ But a natural possibility is of course that the proxy does not perform very well with regard to capturing relevant aspects of legal capacity. Note, however, that the exporter's legal capacity is positively correlated with dispute initiation, as illustrated in Figure 3. An alternative explanation for the lack of significance is that legal capacity is defined through GDP, and thereby highly correlated with the latter. The expected effect of this multicollinearity is precisely that of reducing significance levels. However, even with the GDP variable omitted, exporter's legal capacity is still not significant. Note further that this multicollinearity problem notwithstanding, the importer's GDP and legal capacity are both significant with opposite signs.

There is indeed a seemingly widespread view in the literature that the measures for legal capacity that are available are all rather poor indicators. Hopefully, the survey work that Busch, Reinhardt and Shaffer (2007) has recently been conducting will provide researchers with better information on the exact nature of developing country lack of legal capacity in the WTO system.

\footnotetext{
${ }^{23}$ In contrast, this variable tends to be more significant in the OLS regressions. We can also note that in the present estimation, it also takes on the wrong sign, suggesting that more legal capacity should reduce the expected number of disputes. The latter may at first seem highly counterintuitive. But a possible interpretation of such relationship would be that countries with significant legal capacity deter trading partners from committing illegalities, and therefore face fewer illegalities than countries with less legal capacity. We are for several reasons not convinced about the validity of this argument, however.
} 
Before turning to the other variables, let us just mention that because of the non-linear nature of count models such as this one, the interpretation of the coefficients is a bit more complicated than in the case of e.g. standard OLS, and these matters are further complicated by the fact that our explanatory variables sometimes are in log form. In the case where the explanatory variable appears in log form, the interpretation is simply that of an elasticity: a coefficient value of $\mathrm{k}$ for the explanatory variable $\mathrm{x}$ implies that a one percent change in $\mathrm{x}$ changes the number of ISBDs by $\mathrm{k}$ percent.

With regard to the other explanatory factors examined in the estimation, the theory predicts that exporters with higher GDP tend to initiate more disputes, since higher GDP tends to make enforcement easier, which in turn should tend to increase the expected benefit from pursuing a dispute. The estimated model confirms this hypothesis. Note however that this is not simply capturing a size of exports effect, since exports and its decomposition, enter separately in the regression.

But the size of the importer's GDP also positively affects dispute initiation, contradicting the idea that enforcement is made more difficult by a larger respondent. The latter can plausibly be explained by a weakness in our theory above. It could be argued that larger respondents on average have larger latent import demand, and that all else given, the expected gain from complaining against such a country therefore is larger. A larger market is also likely to be the target of other countries' complaints. This makes it more likely to be the subject of complaints by other countries, in which case it would be easier jointly file a Request for Consultations. It can be noted that importing country GDP not only enters with the wrong sign, but also that the effect is important quantitatively speaking: the positive impact of importing country GDP on expected dispute initiation is in absolute terms larger than the impact of exporting country GDP. These results, taken together with the significantly negative impact of the importer's legal capacity on dispute initiation, are in line with the findings by Guzman and Simmons (2005) that legal capacity seems to be more important for the choice of respondent than "power considerations".

The coefficient for the variable capturing the bilateral aid dependence of the exporter is negative, as theory predicts. The regression thus prima facie seem to confirm that aid 
dependence may be a disciplining factor on dispute initiation, as discussed above. ${ }^{24}$ However, this effect seems implausibly large, most likely due to an endogeneity problem inherent in our econometric model - aid dependence will in effect serve as a general proxy for underdevelopment and may therefore capture various factors influencing the propensity to initiate disputes. In particular, high aid dependence is likely to be correlated to preferential tariff treatment by richer countries. Consequently, the significant coefficient for aid dependence has two interpretations: it may signal the existence of power politics donor countries bully the recipient countries not to react on illegalities - or it may signal absence of illegalities correlated to aid dependence, due to preferential treatment. The estimated coefficient will capture both of these effects. It should be noted that this endogeneity problem is not particular to our model, but is inherent in any model that does not control for preferential treatment (including, for example, Zejan and Bartels (2006)). In addition, since the absolute majority of the observation for disputes and aid are zero, the small existing variation in these variables will make the results sensitive to outliers and omitted variables.

Let us now turn to trade structure. We first note that all the coefficients enter with the expected positive sign. Hence, for each industry, holding the level of exports in other industries constant, more exports are likely to be associated with more dispute initiation. But we can also see that industries differ in the extent to which trade volumes can be expected to increase dispute initiation. The grouping “Agr” stands out as the industry group with the highest propensity, and it can be shown that the coefficient is significantly larger than the other coefficients. ${ }^{25}$ The industry group with the lowest propensity is "Man," where a certain proportional increase in the trade volume is likely to generate two-thirds as many more disputes compared to Agr. We thus conclude that countries' structure of trade across sectors actually is likely to affect their propensity to initiate disputes. We will return

\footnotetext{
${ }^{24}$ As a side remark, if we instead of complainants who initiated disputes consider countries that only filed a request to join consultations, aid dependence is not significant. Hence, the deterrent effect of aid dependence only has a bite for countries that participate in the original Request for Consultations.

${ }^{25}$ This can, for example, be examined by instead running the regression with trade variables

$$
\ln X_{i j g}+\sum_{g \neq A g r} \delta_{g} \beta_{1 g} \ln X_{i j g}
$$

where the second term now measures the divergence from the base case (which is taken to be Agr) for the dispute sensitivity on trade. This formulation is economically and econometrically equivalent to the one employed in the paper, but gives test statistics that directly tell whether an industry is significantly different from the base case. This will be the case whenever its coefficient $\beta_{1 g}$ (for $g$ different from Agr) is significantly different from zero.
} 
to this issue below.

Finally, we note that it can also be shown that the model as a whole is significant at the $1 \%$ level. $^{26} 27$

\subsection{Model predictions concerning participation in the DS system}

Having broadly presented the role of the various explanatory factors as suggested by the estimated model, we will now use the model to predict several aspects of participation.

\subsubsection{Which countries does the model suggest as being over/under-represented as complainants?}

The purpose of the estimation is to determine the set of coefficient values for the different explanatory factors that makes the model predict as closely as possible the actual numbers. In this exercise we are constrained by the mathematical properties that are imposed by the statistical model. The estimation thus determines the set of parameter values that would most likely give rise to the observed data, given the mathematical structure imposed by the statistical model (the negative binomial model, etc.).

In a certain sense, the coefficients can be said to represent the "average” impact of each explanatory factor. That is, they are not determined so as to completely predict a particular observation, such as the impact of Chile's exports in industry group Agr to the US on the expected number of dispute initiations by Chile against the US in this industry group Agr. Instead, the estimated coefficient for Agr will reflect the impact across all bilateral country pairs involving exports of Agr. We can therefore use the difference between the actual number of ISBDs and the predicted number of such disputes for different countries, and in particular country groups, as an indication of whether the country or country group is “under-represented” or "over-represented” with regard to dispute initiation, relative to this "conditional average."

\footnotetext{
${ }^{26}$ As suggested by Pregibon (1980), a model specification test can be done by running a negative binomial regression of the actual ISBD variable on fitted values and squared fitted values. If the latter are significantly different from zero there are indications of a specification error. In this case the p-value is 0.38 , indicating no model specification error. There are reasons to believe however, that there are omitted variables.

${ }^{27}$ As mentioned, the Poisson model is a simpler version of the model employed here, but cannot handle situations with over-dispersion. Indeed, the estimated dispersion parameter is significantly positive (see Table 5), confirming the decision not to use the Poisson model.
} 
Table 6 gives the actual ISBD for each country, and the number that is predicted according to the negative binomial model. As the Table shows, the model performs well in the aggregate in that it predicts only six more disputes than what the data set actually contains. The Table suggests that among the group of "overrepresented” countries are Canada, the EC, Hungary, and the group of Latin-American countries including Chile, Guatemala, Honduras, Mexico, and Panama. At the other end of the spectrum are Australia, China, Japan, Malaysia, South Africa, and Thailand, all of which initiate fewer ISBDs than the average country would given the characteristics of their situation. The US is neither overor underrepresented here. 
Table 6: Actual and predicted number of IBSD by country according to the negative binomial model

\begin{tabular}{|c|c|c|c|c|c|c|c|c|c|c|c|}
\hline Country & Act. & Pred. & Diff & Country & Act. & Pred. & Diff & Country & Act. & Pred. & Diff \\
\hline Albania & 0 & 0.0 & 0.0 & Gabon & 0 & 0.1 & -0.1 & New Zealand & 4 & 2.9 & 1.1 \\
\hline Angola & 0 & 0.1 & -0.1 & Gambia & 0 & 0.0 & 0.0 & Nicaragua & 1 & 0.1 & 0.9 \\
\hline Antigua \& Barb. & 0 & 0.0 & 0.0 & Georgia & 0 & 0.0 & 0.0 & Niger & 0 & 0.0 & 0.0 \\
\hline Argentina & 9 & 8.6 & 0.4 & Ghana & 0 & 0.1 & -0.1 & Nigeria & 0 & 1.0 & -1.0 \\
\hline Armenia & 0 & 0.0 & 0.0 & Grenada & 0 & 0.0 & 0.0 & Norway & 4 & 3.9 & 0.1 \\
\hline Australia & 2 & 8.5 & -6.5 & Guatemala & 5 & 0.7 & 4.3 & Oman & 0 & 0.2 & -0.2 \\
\hline Bahrain & 0 & 0.2 & -0.2 & Guinea & 0 & 0.0 & 0.0 & Pakistan & 3 & 1.4 & 1.6 \\
\hline Bangladesh & 1 & 0.7 & 0.3 & Guinea-Bissau & 0 & 0.0 & 0.0 & Panama & 3 & 0.5 & 2.5 \\
\hline Barbados & 0 & 0.1 & -0.1 & Guyana & 0 & 0.0 & 0.0 & Pap. New Guinea & 0 & 0.1 & -0.1 \\
\hline Belize & 0 & 0.1 & -0.1 & Haiti & 0 & 0.0 & 0.0 & Paraguay & 0 & 0.4 & -0.4 \\
\hline Benin & 0 & 0.0 & 0.0 & Honduras & 5 & 0.2 & 4.8 & Peru & 2 & 1.4 & 0.6 \\
\hline Bolivia & 0 & 0.2 & -0.2 & Hong Kong - Ch. & 1 & 3.2 & -2.2 & Philippines & 4 & 2.3 & 1.7 \\
\hline Botswana & 0 & 0.1 & -0.1 & Hungary & 5 & 1.2 & 3.8 & Poland & 3 & 2.0 & 1.0 \\
\hline Brazil & 16 & 15.2 & 0.8 & Iceland & 0 & 0.6 & -0.6 & Qatar & 0 & 0.2 & -0.2 \\
\hline Brunei Daruss. & 0 & 0.1 & -0.1 & India & 16 & 9.1 & 6.9 & Romania & 0 & 0.7 & -0.7 \\
\hline Bulgaria & 0 & 0.7 & -0.7 & Indonesia & 2 & 6.3 & -4.3 & Rwanda & 0 & 0.0 & 0.0 \\
\hline Burkina Faso & 0 & 0.0 & 0.0 & Israel & 0 & 1.9 & -1.9 & St Kitts \& Nevis & 0 & 0.0 & 0.0 \\
\hline Burundi & 0 & 0.0 & 0.0 & Jamaica & 0 & 0.4 & -0.4 & Saint Lucia & 0 & 0.0 & 0.0 \\
\hline Cambodia & 0 & 0.0 & 0.0 & Japan & 9 & 23.9 & -14.9 & St Vinc. \& Gren. & 0 & 0.0 & 0.0 \\
\hline Cameroon & 0 & 0.2 & -0.2 & Jordan & 0 & 0.1 & -0.1 & Saudi Arabia & 0 & 0.2 & -0.2 \\
\hline Canada & 21 & 16.2 & 4.8 & Kenya & 0 & 0.3 & -0.3 & Senegal & 0 & 0.1 & -0.1 \\
\hline Central Afr. Rep & 0 & 0.0 & 0.0 & Korea & 13 & 10.9 & 2.1 & Sierra Leone & 0 & 0.0 & 0.0 \\
\hline Chad & 0 & 0.0 & 0.0 & Kuwait & 0 & 0.4 & -0.4 & Singapore & 1 & 2.7 & -1.7 \\
\hline Chile & 8 & 3.4 & 4.6 & Kyrgyz Republic & 0 & 0.0 & 0.0 & Slovak Republic & 0 & 0.4 & -0.4 \\
\hline China & 2 & 11.0 & -9.0 & Latvia & 0 & 0.1 & -0.1 & Slovenia & 0 & 0.4 & -0.4 \\
\hline Colombia & 3 & 2.6 & 0.4 & Lesotho & 0 & 0.0 & 0.0 & Solomon Islands & 0 & 0.0 & 0.0 \\
\hline Congo & 0 & 0.1 & -0.1 & Lithuania & 0 & 0.1 & -0.1 & South Africa & 0 & 4.0 & -4.0 \\
\hline Costa Rica & 3 & 1.6 & 1.4 & Macao - China & 0 & 0.2 & -0.2 & Sri Lanka & 1 & 0.7 & 0.3 \\
\hline Croatia & 0 & 0.2 & -0.2 & Madagascar & 0 & 0.1 & -0.1 & Suriname & 0 & 0.0 & 0.0 \\
\hline Cuba & 0 & 0.5 & -0.5 & Malawi & 0 & 0.1 & -0.1 & Swaziland & 0 & 0.1 & -0.1 \\
\hline Cyprus & 0 & 0.1 & -0.1 & Malaysia & 1 & 4.6 & -3.6 & Switzerland & 4 & 4.9 & -0.9 \\
\hline Czech Republic & 1 & 1.1 & -0.1 & Maldives & 0 & 0.0 & 0.0 & Tanzania & 0 & 0.2 & -0.2 \\
\hline Côte d'Ivoire & 0 & 0.6 & -0.6 & Mali & 0 & 0.0 & 0.0 & Thailand & 9 & 6.2 & 2.8 \\
\hline DR Congo & 0 & 0.0 & 0.0 & Malta & 0 & 0.2 & -0.2 & Togo & 0 & 0.0 & 0.0 \\
\hline Djibouti & 0 & 0.0 & 0.0 & Mauritania & 0 & 0.0 & 0.0 & Trinidad and Tob. & 0 & 0.3 & -0.3 \\
\hline Dominica & 0 & 0.0 & 0.0 & Mauritius & 0 & 0.2 & -0.2 & Tunisia & 0 & 0.2 & -0.2 \\
\hline Dominican Rep. & 0 & 0.7 & -0.7 & Mexico & 14 & 11.1 & 2.9 & Turkey & 2 & 4.5 & -2.5 \\
\hline EC & 74 & 61.8 & 12.2 & Moldova & 0 & 0.0 & 0.0 & US & 62 & 63.1 & -1.1 \\
\hline Ecuador & 3 & 1.1 & 1.9 & Mongolia & 0 & 0.0 & 0.0 & Uganda & 0 & 0.1 & -0.1 \\
\hline Egypt & 0 & 0.9 & -0.9 & Morocco & 0 & 0.7 & -0.7 & Un. Arab Emir. & 0 & 1.2 & -1.2 \\
\hline El Salvador & 0 & 0.3 & -0.3 & Mozambique & 0 & 0.1 & -0.1 & Uruguay & 1 & 1.0 & 0.0 \\
\hline Estonia & 0 & 0.1 & -0.1 & Myanmar & 0 & 0.5 & -0.5 & Venezuela & 1 & 2.1 & -1.1 \\
\hline FYROM-Mac. & 0 & 0.0 & 0.0 & Namibia & 0 & 0.1 & -0.1 & Zambia & 0 & 0.0 & 0.0 \\
\hline Fiji & 0 & 0.2 & -0.2 & Nepal & 0 & 0.0 & 0.0 & Zimbabwe & 0 & 0.4 & -0.4 \\
\hline
\end{tabular}

For better overview, Table 7 aggregates the figures in Table 6 over each of the seven country groups we defined in the above: 
Table 7: Actual and predicted number of IBSD according to negative binomial model

$\begin{array}{lccc}\text { Country group } & \text { Actual ISBD } & \text { Pred. ISBD } & \text { Diff } \\ \text { G2 } & 136 & 125 & 11 \\ \text { EI } & 44 & 61 & -17 \\ \text { NI } & 54 & 60 & -6 \\ \text { CT } & 11 & 18 & -7 \\ \text { HID } & 25 & 23 & 2 \\ \text { MID } & 22 & 21 & 1 \\ \text { LID } & 26 & 14 & 12 \\ \text { LDC } & 1 & 2 & -1 \\ \text { Tot } & 319 & 325 & -6\end{array}$

According to this broader picture, the “over-represented” groups are G2 (specifically, the EC), and in proportion to their actual number of ISBDs, in particular the low income developing countries. Three groups of countries are less active as complainants than what is suggested by the volume and pattern of their trade etc: Early Industrialized countries, Countries in Transition, and the Newly Industrialized countries. Again, it should be emphasized that "over-“ and "under-representation” are to be seen relative to the estimated model, not necessarily to an “objective” benchmark.

A few specific remarks about the LDC group are in order. First, in terms of the absolute numbers of disputes, the model does a better job at predicting the actual number of disputes for LDCs than for any other group. Second, the predictions also illustrate intrinsic problems with the kind of approach taken here, as well as in the rest of the literature, when it comes to evaluating the degree of LDC under-representation. The model suggests that LDCs should have $100 \%$ more disputes than they have had, and this group is in this sense actually the most under-represented group among the 7 in the study. However, intuitively it seems to be a different matter for a group of countries to increase the number of complaints from say 40 to 80 , than from 1 to 2 . Also, intuition suggests that the very small number of disputes involved in the case of LDCs leave much more room for randomness than is the case for the other groups, partly since the number of actual disputes has to be an integer number. (Had for some reason LDCs had two complaints, their participation would suddenly be twice as large.) In particular, a transition from zero disputes to one dispute intuitively seems to contain special considerations, due to threshold effects. Our bottom 
line is that while these kinds of models seem able to fairly accurately predict the broader patterns of dispute initiation, they are not suited to determine whether LDCs should on the basis of their trade patterns, legal capacity, etc, have say two or three disputes, rather than one.

\subsubsection{What is the impact of LDC country size on dispute initiation?}

LDCs differ from richer countries in several ways, and each difference may have an impact on dispute initiation. A recurring theme in the literature is the question of whether developing countries participate less as complainants compared to richer countries because of smaller commercial interests, or because of more "structural” factors. The results from the negative binomial model indeed suggest that there is more to the issue than just aggregate trade volume or aggregate bilateral trade volumes. In particular, it was seen that absolute size of the trading economies matters beyond what is captured by trade volumes, and second, that trade structure across industry groups also seem to matter. In this and the next subsection we use the estimated model to shed further light on these issues.

An important aspect of LDCs is that they simultaneously harbor a number of features that alone are each likely to give rise to a low level of dispute initiation: small export volumes, small GDP, legally competent trading partners, aid dependence, etc. There is a strong suspicion on our part that these factors do not only individually contribute to low levels of dispute initiation, but also that they may interact in important ways. Intuitively, the joint effect of the weaknesses is larger than what the "sum of the individual weaknesses" would suggest. One way of examining this issue would be to answer the following question: suppose that all LDCs were merged into an "LDC Union” for the handling of complaints in the DS system. The union would be instructed to base its decisions concerning litigation on the combined exports of its members, and would draw on the combined resources of the countries in other respects. How would this affect the total number of complaints initiated by LDCs? Clearly, in order to answer this we cannot simply consider the simple correlations that the graphs above represent. We need to understand the interplay between the various factors determining dispute initiation. Hence, a relatively simple - but erroneous - way of addressing this issue would be to examine the relationship between export values and dispute initiation for richer countries. Having established this relationship, one could plug in the exports of the LDCs to obtain a certain number of disputes, which most likely would be larger than the actual number of disputes for the 
LDCs. The problem with this method however, is that it does not take into consideration the fact that the richer countries not only have different trade patterns, they are also different in other respects, such as legal capacity, relative power, etc, aspects that the model has shown to matter.

One possible approach to answer the question of what impact the formation of the LDC Union would have is to use the estimated model to compute how much trade such a country would have. We want to emphasize that our calculations are here only meant to be illustrative of the type of analysis that can be performed, with an estimated model of the kind we have here. In order to have full confidence in the actual numbers, much more detailed work is necessary than we have been able to undertake here. In particular, if there are omitted variables that are correlated with the regressors, these are implicitly assumed to change as the value of the regressors change.

Should one not expect the LDC Union to simply initiate the same number of disputes as the LDC do together in its absence? The answer is no, given the non-linear properties of the model. In order to avoid a technical description, let us just say there are forces suggesting that the LCD Union would initiate fewer disputes; for instance, with the coefficients for the export volumes of the various industry groups smaller than unity, the expected number of ISBDs are increasing at a decreasing rate in the volume of any particular industry. Also, intra-LDC trade is not accounted for, which reduces total trade values. On the other hand, because of the interaction between the different explanatory factors, there are tendencies for the opposite.

In order to assess the implication of the formation of the LDC Union we assume more specifically the following. The trade flows are for each industry group, the sum over all members of the LDC Union, excluding of course trade between the LDCs. The GDP influencing its decisions is the sum of the GDP of the individual members. To compute a legal capacity index, we first compute a weighted average of the Government Efficiency variable, using GDP shares. This index is then transformed to a legal capacity index by multiplying the index value with the log of GDP. The aid dependence is the total net aid flows to the countries in the LDC Union, set in relation to the total GDP of the group. We also adjust for the time the countries have been WTO members. Clearly, this is not the only 
way in which we could form a LDC Union. However, they seem to us to represent one natural experiment.

Having constructed the LDC Union along the lines described above, the next step is to use the estimated coefficients from the model to calculate the expected number of disputes it would initiate. ${ }^{28}$ The prediction thus derived is that this country would initiate 4.3 disputes rather than the two disputes that the model predicts that this group of countries would have if acting individually. Again, we want to emphasize that one should not put much faith in the absolute level of this number. What it may shed light on however, are some more qualitative features of dispute initiation, which is that LDCs may have so few disputes not only because of small trade volumes, or because of small own GDP, but also because of the interaction between such explanatory factors. Loosely put: the fact that simultaneously both LDC export volumes and GDP levels (and other factors affecting the number of ISBDs) are small is what makes things particularly bad from a dispute initiation point of view. Collectively, the factors that define underdevelopment work together to drive down participation in the DS system in a predictable fashion.

\subsubsection{What is the impact of the LDC composition of exports on dispute initiation?}

A common perception in the policy literature seems to be the notion that part of the reason why developing countries participate less as complainants is that their trade compositions differ from those of richer countries. To shed some light on the validity of this claim, we use the estimated model to undertake the thought experiment of assuming that the industry export shares of the LDC Union formed in the previous subsection, are changed so as to replicate export shares of richer countries while maintaining a constant total volume of exports. The idea is hence to neutralize for absolute trade volume, and to focus on the effect of the industry structure per se. More specifically, we first compute the unweighted average of the share of each the industry groups in total exports for across the three groups of richer countries G2, EI and NI. ${ }^{29}$ We then ask how many disputes the LDC Union would have if its total export volume were the same as computed before, but with the richer country composition of these exports.

\footnotetext{
${ }^{28}$ This procedure could be criticized on the ground that the coefficients would be different if estimated with the LDC Union in place. But we believe that it would not make much difference to the results quantitatively, since the LDC are small also in the aggregate relative to the other countries.

${ }^{29}$ An alternative to using an unweighted scheme would be to simply aggregate over the three groups (this would in turn of course be equivalent to using total exports as weights when computing the average). This would imply that the G2 export structure would dominate the computed shares.
} 
As it turns out, the trade structure of the LDCs seems to have a very limited impact on their dispute initiation. As mentioned above, the LDC Union would be expected to initiate approximately 4.3 disputes with the actual trade structure of these countries. Taking the further step of changing the structure to that of the developed countries would only increase the number of expected disputes to just under five. Hence, it seems as if the composition of LDC exports in itself is not a very important factor explaining the limited participation. Of course, we should be very careful not to draw far-reaching policy conclusions based on this finding. For instance, even if we trusted the number (which we should not do without much further verification), we should not jump to the conclusion that the problem of what appears to be too low levels of dispute initiation is explained partly or fully by other factors than trade structure. It may well be that our very broad industry groups in actuality encompass significant intra-group differences. To address this problem, we would need a much more refined industry classification. But we have deliberately chosen a fairly coarse industry classification, partly for the sake of expositional clarity, and partly in order to aggregate away noise in the data. Also, if we were to find that the composition seems to matter we would have to determine why this is the case, in order to draw any policy conclusions. For instance, this might reflect other differences between developed and developing countries that are endogenously captured by the included regressors.

\subsection{Other econometric approaches}

Our conclusion from the above is that the negative binomial model seems to be doing a fairly good job. Nonetheless, it is likely that it will not be able to fully handle the problems caused by the very large number of zeros. There are techniques however, that are meant to address the problem with a large number of zeros more directly. A prominent candidate here is an extension of the model, the "zero-inflated negative binomial model." Applied to the present context, an essential feature of this approach is to view the determination of the number of dispute initiations as two separate processes. One determines whether a country is active at all as a potential complainant, and the second determines the number of disputes that the country has over a certain period, given that it decides in the first process to potentially participate. A zero-participation for a country can then result either from a decision to not participate at all, or from a decision to potentially participate combined with a decision not to launch any complaints despite the readiness to do so. 
This view of dispute initiation seems to us to resonate well with the popular notion that some countries - in particular LDCs - are not even potentially complainants, but are completely outside the system. For instance, it has been forcefully argued by Shaffer (2003) that for the reasons discussed above, as well as some additional factors, the poorest WTO Members are effectively not active players as potential litigants in the DS system. They have nothing to litigate over.

The zero-inflated negative binomial model regression model thus seems to be pertinent for the issue at stake both from a theoretical and from an intuitive point of view. We have spent considerable efforts to estimate such models, using the data presented above. But our attempts have to not been very successful. ${ }^{30}$ We therefore leave this area for future research (perhaps in future when we have deeper datasets and better solution methods for these models). However, we want to emphasize that the dominance of zeros in the data is a feature that needs to be addressed in future work in this area. ${ }^{31}$

\section{Concluding remarks}

There has been an undercurrent of worry around the WTO DS mechanism since its inception. In particular, there has been alleged that the system is biased against developing countries, and there have been proposals for reform of the system to remedy such perceived biases, particularly in dispute initiation. The starting point of research in this area is therefore a seemingly simple question. "Do developing countries use the DS mechanism less than they 'should' based on objective criteria?”

\footnotetext{
${ }^{30}$ At some instance, the maximum likelihood estimations that are used do not converge. At other instances, the models produce absurd predictions. We believe that these features may stem from the fact that the zeroinflated negative binomial model combines two more primitive models, a count data model, and a probability model. Count data models and binary response models (BRM) have different underlying assumptions. When combined, as in the zero-inflated negative binomial model, their interaction may have effects on robustness that do not seem to have been sufficiently explored in the literature. In particular BRMs makes strong assumptions concerning correct specification and marginal effects of the regressors. In cases when endogeneity is present, the maximum likelihood estimator performs notoriously bad. (See Hall and Shen (2005).)

${ }^{31}$ It should be said that binary response models (probit and logit) to a certain degree solve this problem by only reflecting whether or not a dispute has occurred. This is done at the cost of disregarding a significant amount of information, however, and the results can therefore be quite misleading.
} 
In our empirical analysis, we have tried to highlight aspects of this question, by improving on the earlier literature in several respects. First, we use a much richer dispute data set than has been used so far in the literature, by including all dispute initiation during the period 1995-2006. Second, we focus more on the role of industrial structure than has been done in the literature. Third, we employ econometric techniques that, while not entirely new in the field, are more suitable to the situation at hand than what is often used. Our results suggest that the composition of trade, the volume of trade, income levels, aid levels, and legal capacity, explain the observed aggregate level of dispute initiation fairly well. Predictions from the estimated model also suggest that Low Income Developing countries, as defined in Table 1, have launched more complaints than they should have, based on these characteristics.

Fourth, we use the estimated model to answer two fundamental questions concerning the determinants of Least Developed Country participation as complainants, questions that to the best of our knowledge have not been highlighted in the literature. Our first question concerns the role of economic country size. It is often said that since LDCs typically are very small in terms of GDP, in terms of trade, etc, that they do not have incentives to launch disputes. We therefore make the thought-experiment of merging all LDCs into an “LDC Union” for the handling of complaints in the DS system. This Union is instructed to base its decisions concerning litigation on the combined exports of its members, and would draw on the combined resources of the countries in other respects. The model predicts that a country with the characteristics of this "LDC Union” would have initiated 4.3 disputes rather than the two disputes that the model predicts that this group of countries would have launched if acting individually. One should be careful not to over-emphasize the validity of these numbers. More interesting is that this experiment suggests that LDCs may have so few disputes not only because of small trade volumes, or because of small GDP levels, but also because of the interaction between such explanatory factors.

The second issue upon which we seek to shed light is the common perception in the policy literature that the LDC trade composition explains their seemingly low participation rates. To this end we make the further thought experiment of letting the export structure of this "LDC Union” be the same as the average of the exports of G2, Earlier Industrialized and Newly Industrialized countries, while keeping the total volume of exports unchanged. This "LDC Union” is hence in terms of industry export structure a replica of the richer countries, 
but is in other respects an aggregation of LDCs. Using the estimated model, this change in export composition would increase the number of disputes by roughly $15 \%$. This suggests that export composition has a fairly limited impact on the dispute initiation by LDC, contrary to what is often suggested.

We would finally like to emphasize the great caution that is needed when drawing policy conclusions based on observations concerning dispute initiation in the DS system. Such conclusions are inevitably based on a number of special assumptions that are typically not made explicit. For instance, there are conceptual problems with regard to the definition of the unit of account ("a dispute”) as well as relevant benchmarks, there are econometric problems with regard to how to distinguish the determinants of dispute initiation as well as how to handle the dominance of zeros in the data, there are data availability problems with regard to a number of important variables such as legal capacity and power. In addition, there are conceptual problems with regard to how to frame relevant and well-defined questions that can be answered within the model. We have here tried to address some of these problems, but most still remain. 


\section{REFERENCES}

Blonigen, B. and C. Bown (2003). “Antidumping and retaliation threats”, Journal of International Economics, 60: 249 - 273.

Bown, C. (2002). “The economics of trade disputes, the GATT's Article XXIII and the WTO’s dispute settlement understanding”, Economics and Politics, 14: 283 - 323.

Bown, C. (2004a). “On the economic success of GATT/WTO dispute settlement”, The Review of Economics and Statistics, 37: 678 - 720.

Bown, C. (2004b). "Developing countries as plaintiffs and defendants in GATT/WTO trade disputes”, The World Economy, 27: 59 - 80.

Bown, C. (2005). "Participation in WTO dispute settlement: complainants, interested parties and free riders”, World Bank Economic Review, 19: 287-310.

Busch, M. and E. Reinhardt (2002). "Testing international trade law: empirical studies of GATT/WTO dispute settlement”, in Daniel Kennedy and James Southwick (eds.), The political economy of international trade law, essays in honour of Robert E. Hudec, Cambridge University Press, Cambridge, Mass.

Bütler, M. and H. Hauser (2000). "The WTO dispute settlement system: A first assessment from an economic perspective”, Journal of Law, Economics \& Organization, 16: 503-533.

Cameron, A.C. and P.K. Trivedi (1998). Regression Analysis of Count Data, New York: Cambridge University Press.

Francois, J., B. Hoekman and M. Manchin (2006). "Preference erosion and multilateral trade liberalization,” World Bank Economic Review.

Francois and Manchin (2007). “Trade, Institutions, and Infrastructure,” CEPR discussion paper.

Grinols, E. and R. Perrelli (2003). "The WTO impact on international trade disputes: an event history analysis”, The Review of Economics and Statistics, forthcoming.

Guzman, A. (2003). “The political economy of litigation and settlement at the WTO”, mimeo.

Guzman, A. and B. Simmons (2005). "Power plays and capacity constraints: the selection of defendants in WTO disputes”, Journal of Legal Studies 34, 557 - 598.

Hall, D.B. and J. Shen (2005). “Robust Estimation for Zero-Inflated Regression Models”, lecture at International Statistics Conference of 2005.

Hoekman, B., Horn, H. and P. Mavroidis (2007). "Winners and losers in the WTO Dispute Settlement system”, mimeo. 
Horn, H. and P.C. Mavroidis (2007). “International trade - Dispute settlement”, in Sykes, A. and A. Guzman (eds), Research Handbook of International Economic Law, Edward Elgar Publishing.

Horn, H., Nordström, H. and P.C Mavroidis (1999). "Is the use of the WTO dispute settlement system biased?”, CEPR Discussion Paper Series No 2340.

Pregibon, D. (1980). “Goodness of link tests for generalized linear models”, Applied Statistics 29, 15-24.

Nordström, H. and G. Shaffer (2007). "Access to Justice in the World Trade Organization: The Case for a Small Claims Procedure - A Preliminary Analysis”. Issue Paper No. 2, International Centre for Trade and Sustainable Development.

Reinhardt, E. (2000). “Aggressive multilateralism: the determinants of GATT/WTO dispute initiation 1948 - 1998”. Mimeo.

Shaffer, G. (2003). "How to Make the WTO Dispute Settlement System Work for Developing Countries: Some Proactive Developing Country Strategies”. In Towards A Development-Supportive Dispute Settlement System in the WTO, Resource Paper No. 5, International Centre for Trade and Sustainable Development.

Zejan, P. and F. Bartels (2006). "Be nice and get your money - An empirical analysis of World Trade Organization disputes and aid”, Journal of World Trade 40(6), 1021-1047. 
Table A-1: Total exports in \$US mill and the fraction thereof for each industry group

(see note below)

\begin{tabular}{|c|c|c|c|c|c|c|c|c|c|c|c|c|c|c|c|c|}
\hline Complainant & Total & $\begin{array}{l}\text { to } \\
\sum_{1} \\
\Xi\end{array}$ & $\tilde{U}_{1}$ & $\begin{array}{l}\text { ปี } \\
\text { บิ }\end{array}$ & $\sum_{\Xi}^{\Xi}$ & $\bar{\Sigma}_{1}^{\tilde{E}}$ & 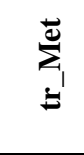 & $\begin{array}{l}\sum_{1}^{J} \\
\Xi\end{array}$ & $\sum_{1}^{\mathcal{N}}$ & $\tilde{\partial}$ & $\stackrel{\pi}{2}$ & $\frac{\pi}{2}$ & $\bar{m}$ & $\stackrel{x}{-x}$ & $\bar{z}$ & $\stackrel{8}{3}$ \\
\hline Albania & 311 & 0.10 & 0.00 & 0.00 & 0.02 & 0.07 & 0.05 & 0.03 & 0.31 & 0.01 & .00 & 0.01 & 0.05 & .31 & 0.01 & 0.04 \\
\hline Angola & 6020 & 0.01 & 0.00 & 0.00 & 0.00 & 0.00 & 0.00 & 0.90 & 0.00 & 0.09 & 0.00 & 0.00 & 0.00 & 0.00 & 0.00 & .00 \\
\hline Ant.and Barb. & 147 & 0.08 & 0.00 & 0.01 & 0.00 & 0.02 & 0.00 & 0.11 & 0.00 & 0.00 & 0.00 & 0.02 & 0.01 & 0.01 & 0.73 & 0.00 \\
\hline Argentina & 25400 & 0.48 & 0.02 & 0.02 & 0.01 & 0.04 & 0.02 & 0.18 & 0.03 & 0.00 & 0.02 & 0.03 & 0.04 & 0.02 & 0.08 & 0.02 \\
\hline Armenia & 170 & 0.03 & 0.00 & 0.00 & 0.01 & 0.02 & 0.07 & 0.11 & 0.00 & 0.60 & 0.00 & 0.00 & 0.04 & 0.08 & 0.01 & .01 \\
\hline Australia & 57600 & 0.22 & 0.05 & 0.02 & 0.02 & 0.06 & 0.08 & 0.32 & 0.01 & 0.05 & 0.02 & 0.01 & 0.02 & 0.06 & 0.04 & .02 \\
\hline Bahrain & 2530 & 0.02 & 0.05 & 0.00 & 0.01 & 0.03 & 0.27 & 0.46 & 0.00 & 0.03 & 0.00 & 0.01 & 0.01 & 0.09 & 0.01 & 0.01 \\
\hline Bangladesh & 5890 & 0.07 & 0.01 & 0.00 & 0.01 & 0.01 & 0.00 & 0.00 & 0.04 & 0.00 & 0.00 & 0.00 & 0.00 & 0.86 & 0.00 & 0.00 \\
\hline Barbados & 296 & 0.24 & 0.02 & 0.05 & 0.05 & 0.13 & 0.04 & 0.29 & 0.00 & 0.01 & 0.02 & 0.01 & 0.01 & 0.02 & 0.08 & 0.04 \\
\hline Belize & 293 & 0.79 & 0.01 & 0.00 & 0.00 & 0.03 & 0.00 & 0.01 & 0.00 & 0.00 & 0.02 & 0.01 & 0.02 & 0.07 & 0.02 & .02 \\
\hline Benin & 286 & 0.21 & 0.01 & 0.01 & 0.00 & 0.00 & 0.00 & 0.04 & 0.04 & 0.01 & 0.00 & 0.00 & 0.00 & 0.64 & 0.00 & .02 \\
\hline Bolivia & 1020 & 0.38 & 0.01 & 0.00 & 0.01 & 0.01 & 0.06 & 0.33 & 0.02 & 0.08 & 0.00 & 0.00 & 0.00 & 0.05 & 0.00 & 0.05 \\
\hline Botswana & 1270 & 0.04 & 0.00 & 0.00 & 0.00 & 0.02 & 0.07 & 0.01 & 0.00 & 0.82 & 0.00 & 0.00 & 0.00 & 0.02 & 0.00 & 0.00 \\
\hline Brazil & 54600 & 0.27 & 0.03 & 0.02 & 0.02 & 0.12 & 0.04 & 0.12 & 0.05 & 0.01 & 0.01 & 0.03 & 0.07 & 0.02 & 0.12 & 0.08 \\
\hline Brunei I & 3080 & 0.00 & 0.00 & 0.00 & 0.01 & 0.00 & 0.00 & 0.86 & 0.00 & 0.03 & 0.00 & 0.00 & 0.00 & 0.09 & 0.01 & 0.00 \\
\hline Bulgaria & 4380 & 0.12 & 0.07 & 0.01 & 0.03 & 0.09 & 0.11 & 0.11 & 0.04 & 0.01 & 0.01 & 03 & 0.10 & 0.24 & 0.01 & 0.03 \\
\hline Burkina Faso & 223 & 0.24 & 0.00 & 0.01 & 0.01 & 0.04 & 0.00 & 0.01 & 0.05 & 0.03 & 0.01 & 0.02 & 0.01 & 0.51 & 0.05 & 0.01 \\
\hline Burundi & 56 & 0.78 & 0.01 & 0.00 & 0.00 & 0.02 & 0.00 & 0.07 & 0.01 & 0.06 & 0.00 & 0.00 & 0.01 & 0.01 & 0.01 & 0.01 \\
\hline Cambodia & 1410 & 0.02 & 0.00 & 0.00 & 0.00 & 0.00 & 0.00 & 0.00 & 0.07 & 0.01 & 0.00 & 0.02 & 0.00 & 0.84 & 0.00 & 0.04 \\
\hline & 2020 & 0.22 & 0. & 0.00 & 0.00 & & & & & & 0.00 & & 0.00 & 05 & 00 & .27 \\
\hline Canada & 240000 & 0.08 & 0.02 & 0.01 & 0.04 & 0.16 & 0.04 & 0.14 & 0.00 & 0.02 & 0.01 & 0.04 & 0.03 & 0.02 & 0.26 & 0.13 \\
\hline Central Afr. Rep & 202 & 0.05 & 0.01 & 0.00 & 0.00 & 0.01 & 0.00 & 0.00 & 0.00 & 0.68 & 0.00 & 0.00 & 0.00 & 0.07 & 0.00 & 0.16 \\
\hline Chad & 102 & 0.16 & 0.00 & 0.00 & 0.00 & 0.01 & 0.00 & 0.00 & 0.00 & 0.00 & 0.00 & 0.00 & 0.00 & 0.79 & 0.02 & 0.00 \\
\hline Chile & 17100 & 0.33 & 0.05 & 0.00 & 0.01 & & 0.25 & 0.15 & 0.00 & 0.02 & 0.01 & 01 & 0.01 & 0.01 & .01 & .13 \\
\hline China & 368000 & 0.04 & 0.02 & 0.01 & 0.17 & 0.32 & 0.03 & 0.04 & 0.10 & 0.01 & 0.00 & 0.03 & 0.02 & 0.17 & 0.01 & 0.02 \\
\hline Colombia & 12900 & 0.29 & 0.01 & 0.04 & 0.01 & 0.02 & 0.01 & 0.40 & 0.01 & 0.03 & 0.02 & 0.03 & 0.02 & 0.06 & 0.02 & 0.02 \\
\hline Congo & 1760 & 0.02 & 0.00 & 0.00 & 0.00 & 0.00 & 0.02 & 0.83 & 0.00 & 0.04 & 0.00 & 0.00 & 0.00 & 0.00 & 0.00 & 0.07 \\
\hline Costa Ric & 6750 & 0.39 & 0.00 & 0.02 & 0.04 & 0.32 & 0.01 & 0.01 & 0.01 & 0.01 & 0.01 & .03 & 0.01 & 0.13 & .00 & .01 \\
\hline Croatia & 3040 & 0.08 & 0.06 & 0.01 & 0.06 & 0.12 & 0.03 & 0.12 & 0.07 & 0.01 & 0.02 & 0.06 & 0.04 & 0.19 & 0.03 & 0.10 \\
\hline Cuba & 978 & 0.55 & 0.03 & 0.00 & 0.00 & 0.01 & 0.07 & 0.24 & 0.00 & 0.01 & 0.02 & 0.00 & 0.05 & 0.00 & 0.00 & 0.00 \\
\hline Cyprus & 870 & 0.20 & 0.02 & 0.01 & 0.05 & 0.12 & 0.03 & 0.06 & 0.02 & 0.02 & 0.05 & 0.01 & 0.02 & 0.09 & 0.29 & 0.01 \\
\hline Czech Republic & 28500 & 0.04 & 0.03 & 0.02 & 0.07 & 0.29 & 0.03 & 0.07 & 0.01 & 0.01 & 0.01 & 0.06 & 0.09 & 0.06 & 0.17 & 0.05 \\
\hline Côte d'Ivoire & 4220 & 0.62 & 0.01 & 0.01 & 0.00 & 0.00 & 0.00 & 0.16 & 0.00 & 0.02 & 0.00 & 0.03 & 0.01 & 0.04 & 0.00 & 0.09 \\
\hline DR Congo & 1180 & 0.04 & 0.00 & 0.00 & 0.00 & 0.00 & 0.08 & 0.23 & 0.00 & 0.61 & 0.00 & 0.00 & 0.00 & 0.00 & 0.00 & 0.03 \\
\hline Djibouti & 18 & 0.30 & 0.01 & 0.02 & 0.02 & 0.07 & 0.03 & 0.06 & 0.12 & 0.11 & 0.10 & 0.01 & 0.04 & 0.01 & 0.08 & 0.01 \\
\hline Dominica & 89 & 0.31 & 0.05 & 0.23 & 0.03 & 0.11 & 0.01 & 0.05 & 0.01 & 0.01 & 0.09 & 0.02 & 0.04 & 0.02 & 0.02 & 0.01 \\
\hline Dominican & 4870 & 0.14 & 0.01 & 0.00 & 0.09 & 0.08 & 0.01 & 0.00 & 0.06 & 0.04 & 0.00 & 0.01 & 0.04 & 0.51 & 0.00 & 0.00 \\
\hline EC & 753000 & 0.06 & 0.06 & 0.03 & 0.06 & 0.31 & 0.03 & 0.05 & 0.02 & 0.04 & 0.05 & 0.04 & 0.04 & 0.05 & 0.13 & 0.03 \\
\hline Ecuador & 5680 & 0.56 & 0.00 & 0.00 & 0.01 & 0.01 & 0.00 & 0.34 & 0.00 & 0.00 & 0.01 & 0.01 & 0.01 & 0.02 & 0.01 & 0.02 \\
\hline Egypt & 5310 & 0.12 & 0.04 & 0.00 & 0.02 & 0.03 & 0.04 & 0.41 & 0.01 & 0.01 & 0.01 & 0.02 & 0.04 & 0.26 & 0.00 & 0.00 \\
\hline El Salvador & 2860 & 0.19 & 0.00 & 0.03 & 0.01 & 0.04 & 0.02 & 0.02 & 0.01 & 0.00 & 0.02 & 0.02 & 0.02 & 0.58 & 0.01 & 0.03 \\
\hline Estonia & 3590 & 0.06 & 0.02 & 0.01 & 0.08 & 0.22 & 0.02 & 0.22 & 0.02 & 0.02 & 0.01 & 0.01 & 0.05 & 0.10 & 0.03 & 0.14 \\
\hline FYROM-Mac. & 962 & 0.14 & 0.01 & 0.00 & 0.01 & 0.05 & 0.08 & 0.03 & 0.06 & 0.01 & 0.01 & 0.00 & 0.20 & 0.36 & 0.04 & 0.01 \\
\hline Fiji & 532 & 0.44 & 0.00 & 0.00 & 0.01 & 0.01 & 0.00 & 0.00 & 0.03 & 0.07 & 0.00 & 0.00 & 0.00 & 0.39 & 0.00 & 0.05 \\
\hline Gabon & 2920 & 0.01 & 0.00 & 0.00 & 0.00 & 0.00 & 0.00 & 0.80 & 0.00 & 0.00 & 0.00 & 0.00 & 0.00 & 0.00 & 0.01 & 0.18 \\
\hline
\end{tabular}


Table A-1 cont'd

\begin{tabular}{|c|c|c|c|c|c|c|c|c|c|c|c|c|c|c|c|c|}
\hline Complainant & Total & $\underbrace{50}_{1}$ & $\mathcal{U}_{1}$ & $\begin{array}{l}\text { בิ } \\
\text { บิ }\end{array}$ & 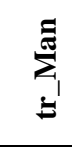 & 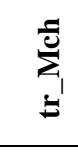 & 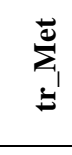 & $\sum_{1}^{J}$ & $\begin{array}{l}\underset{\sum}{\mathcal{N}} \\
\sum_{1}\end{array}$ & 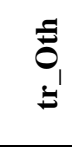 & $\frac{\pi}{2}$ & $\frac{\pi}{2}$ & $\begin{array}{l}\overrightarrow{\omega_{1}} \\
\vec{b}^{\prime}\end{array}$ & $\stackrel{\bar{x}}{*}$ & $\sum_{1}^{2}$ & $\stackrel{8}{3}$ \\
\hline Gambia & 83 & 0.33 & 0.00 & 0.00 & 0.00 & 0.07 & 0.00 & 0.01 & 0.00 & 0.51 & 0.00 & 0.00 & 0.00 & 0.02 & 0.01 & 0.03 \\
\hline Georgia & 397 & 0.09 & 0.04 & 0.00 & 0.01 & 0.05 & 0.06 & 0.46 & 0.00 & 0.02 & 0.01 & 0.01 & 0.17 & 0.01 & 0.01 & 0.05 \\
\hline Ghana & 1500 & 0.50 & 0.00 & 0.00 & 0.01 & 0.01 & 0.12 & 0.09 & 0.00 & 0.07 & 0.00 & 0.00 & 0.00 & 0.01 & 0.04 & 0.14 \\
\hline Grenada & 55 & 0.50 & 0.01 & 0.01 & 0.02 & 0.23 & 0.01 & 0.07 & 0.00 & 0.00 & 0.02 & 0.01 & 0.02 & 0.02 & 0.06 & 0.04 \\
\hline Guatemala & 4600 & 0.42 & 0.01 & 0.04 & 0.01 & 0.01 & 0.00 & 0.05 & 0.01 & 0.01 & 0.03 & 0.03 & 0.03 & 0.34 & 0.00 & 0.02 \\
\hline Guinea & 777 & 0.09 & 0.07 & 0.00 & 0.00 & 0.00 & 0.00 & 0.60 & 0.00 & 0.20 & 0.00 & 0.00 & 0.00 & 0.01 & 0.00 & 0.01 \\
\hline Guinea-E & 97 & 0.45 & 0.00 & 0.00 & 0.00 & 0.01 & 0.00 & 0.47 & 0.00 & 0.00 & 0.00 & 0.00 & 0.00 & 0.02 & 0.02 & 0.02 \\
\hline Guyana & 579 & 0.47 & 0.00 & 0.01 & 0.01 & 0.00 & 0.00 & 0.14 & 0.00 & 0.26 & 0.00 & 0.00 & 0.00 & 0.02 & 0.01 & 0.08 \\
\hline Haiti & 322 & 0.12 & 0.00 & 0.00 & 0.01 & 0.01 & 0.01 & 0.00 & 0.02 & 0.00 & 0.02 & 0.00 & 0.01 & 0.79 & 0.00 & 0.00 \\
\hline Honduras & 3970 & 0.27 & 0.00 & 0.01 & 0.02 & 0.02 & 0.00 & 0.01 & 0.00 & 0.01 & 0.00 & 0.01 & 0.01 & 0.61 & 0.01 & 0.02 \\
\hline HK-China & 51100 & 0.01 & 0.00 & 0.01 & 0.11 & 0.37 & 0.02 & 0.01 & 0.03 & 0.09 & 0.00 & 0.03 & 0.01 & 0.28 & 0.01 & 0.01 \\
\hline Hungary & 27300 & 0.08 & 0.04 & 0.01 & 0.04 & 0.49 & 0.03 & 0.03 & 0.02 & 0.00 & 0.01 & 0.04 & 0.03 & 0.05 & 0.10 & 0.02 \\
\hline Iceland & 2170 & 0.68 & 0.00 & 0.00 & 0.02 & 0.04 & 0.16 & 0.01 & 0.01 & 0.00 & 0.01 & 0.00 & 0.03 & 0.01 & 0.01 & 0.00 \\
\hline India & 43200 & 0.15 & 0.06 & 0.02 & 0.02 & 0.07 & 0.02 & 0.07 & 0.05 & 0.18 & 0.02 & 0.02 & 0.05 & 0.25 & 0.02 & 0.01 \\
\hline Indonesia & 56400 & 0.11 & 0.02 & 0.01 & 0.05 & 0.14 & 0.02 & 0.27 & 0.04 & 0.01 & 0.00 & 0.04 & 0.01 & 0.13 & 0.01 & 0.12 \\
\hline Israel & 26300 & 0.05 & 0.07 & 0.01 & 0.08 & 0.26 & 0.03 & 0.02 & 0.00 & 0.33 & 0.03 & 0.04 & 0.00 & 0.05 & 0.02 & 0.00 \\
\hline Jamaica & 1580 & 0.23 & 0.40 & 0.00 & 0.00 & 0.01 & 0.00 & 0.10 & 0.00 & 0.00 & 0.00 & 0.00 & 0.00 & 0.22 & 0.00 & 0.00 \\
\hline Japan & 13000 & 0.01 & 0.03 & 0.03 & 0.09 & 0.48 & 0.02 & 0.01 & 0.00 & 0.01 & 0.01 & 0.04 & 0.04 & 0.02 & 0.22 & 0.01 \\
\hline Jordan & 1180 & 0.13 & 0.31 & 0.01 & 0.02 & 0.04 & 0.02 & 0.18 & 0.01 & 0.03 & 0.06 & 0.02 & 0.01 & 0.14 & 0.02 & 0.02 \\
\hline Kenya & 1770 & 0.60 & 0.02 & 0.01 & 0.01 & 0.03 & 0.01 & 0.15 & 0.02 & 0.01 & 0.01 & 0.01 & 0.02 & 0.06 & 0.01 & 0.02 \\
\hline Korea & 139000 & 0.02 & 0.03 & 0.01 & 0.03 & 0.46 & 0.02 & 0.05 & 0.02 & 0.01 & 0.00 & 0.06 & 0.06 & 0.10 & 0.11 & 0.01 \\
\hline & 700 & 0.00 & 0.02 & 0.00 & & & & & & & 0.00 & 2 & & & 0 & 0.00 \\
\hline Kyrgyz & 197 & 0.03 & 0.02 & 0.00 & 0.00 & 0.02 & 0.15 & 0.01 & 0.04 & 0.54 & 0.00 & 0.00 & 0.05 & 0.12 & 0.00 & 0.00 \\
\hline Latvia & 2730 & 0.04 & 0.03 & 0.01 & 0.04 & 0.03 & 0.02 & 0.31 & 0.01 & 0.01 & 0.01 & 0.01 & 0.06 & 0.12 & 0.01 & 0.28 \\
\hline Lesotho & 265 & 0.01 & 0.00 & 0.00 & 0.00 & 0.01 & 0.00 & 0.01 & 0.00 & 0.04 & 0.00 & 0.00 & 0.00 & 0.93 & 0.00 & 0.00 \\
\hline Lithı & 3200 & 0.10 & 0 . & 0.01 & & & & & & 3 & 0.01 & 1 & & 24 & 22 & 0.08 \\
\hline Macao - Chin & 2350 & 0.01 & 0.01 & 0.00 & 0.02 & 0.04 & 0.00 & 0.01 & 0.06 & 0.00 & 0.00 & 0.00 & 0.00 & 0.83 & 0.00 & 0.00 \\
\hline Madagascar & 869 & 0.50 & 0.00 & 0.00 & 0.01 & 0.01 & 0.00 & 0.03 & 0.01 & 0.01 & 0.01 & 0.00 & 0.00 & 0.40 & 0.00 & 0.02 \\
\hline Malawi & 456 & 0.89 & 0.00 & 0.00 & 0.00 & 0.01 & 0.00 & 0.01 & 0.00 & 0.00 & 0.00 & 0.00 & 0.00 & 0.08 & 0.01 & 0.00 \\
\hline Mala & 9900 & 0.06 & 0.01 & 0.01 & & 0 . & & 0.08 & & 01 & 0.00 & 0.04 & 01 & 03 & 0.01 & 0.04 \\
\hline Maldives & 170 & 0.30 & 0.00 & 0.00 & 0.00 & 0.01 & 0.00 & 0.00 & 0.00 & 0.00 & 0.00 & 0.01 & 0.00 & 0.66 & 0.00 & 0.00 \\
\hline Mali & 238 & 0.06 & 0.00 & 0.00 & 0.01 & 0.10 & 0.00 & 0.00 & 0.02 & 0.03 & 0.00 & 0.01 & 0.00 & 0.74 & 0.01 & 0.01 \\
\hline Malta & 2170 & 0.02 & 0.00 & 0.00 & 0.06 & 0.61 & 0.00 & 0.05 & 0.02 & 0.03 & 0.00 & 0.04 & 0.01 & 0.09 & 0.07 & 0.00 \\
\hline Mauritania & 578 & 0.53 & 0.00 & 0.00 & & 0.01 & 0.00 & 0.43 & 0 & 0.00 & 0.00 & 0.00 & .00 & .01 & 0.00 & 0.00 \\
\hline Mauritius & 1660 & 0.27 & 0.01 & 0.00 & 0.03 & 0.01 & 0.00 & 0.00 & 0.00 & 0.06 & 0.00 & 0.00 & 0.00 & 0.59 & 0.01 & 0.00 \\
\hline Mexico & 41000 & 0.06 & 0.01 & 0.01 & 0.07 & 0.40 & 0.02 & 0.10 & 0.01 & 0.01 & 0.01 & 0.02 & 0.02 & 0.07 & 0.19 & 0.01 \\
\hline Moldova & 385 & 0.24 & 0.00 & 0.00 & 0.02 & 0.02 & 0.03 & 0.02 & 0.07 & 0.00 & 0.01 & 0.00 & 0.26 & 0.31 & 0.01 & 0.00 \\
\hline Mongolia & 398 & 0.02 & 0.00 & 0.00 & 0.00 & 0.00 & 0.01 & 0.42 & 0.04 & 0.03 & 0.00 & 0.00 & 0.01 & 0.45 & 0.00 & 0.02 \\
\hline Morocco & 7950 & 0.22 & 0.11 & 0.00 & 0.01 & 0.12 & 0.01 & 0.11 & 0.03 & 0.01 & 0.00 & 0.00 & 0.01 & 0.34 & 0.01 & 0.01 \\
\hline Mozambiqu & 586 & 0.33 & 0.00 & 0.00 & 0.00 & 0.02 & 0.37 & 0.17 & 0.00 & 0.00 & 0.00 & 0.00 & 0.01 & 0.05 & 0.01 & 0.04 \\
\hline Myanmar & 2000 & 0.25 & 0.00 & 0.00 & 0.01 & 0.01 & 0.02 & 0.17 & 0.01 & 0.02 & 0.00 & 0.01 & 0.00 & 0.31 & 0.00 & 0.19 \\
\hline Namibia & 770 & 0.48 & 0.08 & 0.00 & 0.00 & 0.01 & 0.04 & 0.07 & 0.02 & 0.28 & 0.00 & 0.00 & 0.00 & 0.00 & 0.01 & 0.00 \\
\hline Nepal & 632 & 0.16 & 0.00 & 0.02 & 0.01 & 0.01 & 0.03 & 0.00 & 0.02 & 0.02 & 0.07 & 0.02 & 0.02 & 0.59 & 0.00 & 0.02 \\
\hline New Zealand & 13600 & 0.50 & 0.02 & 0.05 & 0.02 & 0.07 & 0.05 & 0.03 & 0.03 & 0.01 & 0.01 & 0.02 & 0.02 & 0.05 & 0.01 & 0.13 \\
\hline Nicaragua & 976 & 0.52 & 0.01 & 0.00 & 0.00 & 0.01 & 0.00 & 0.02 & 0.01 & 0.03 & 0.00 & 0.00 & 0.01 & 0.36 & 0.00 & 0.02 \\
\hline Niger & 267 & 0.05 & 0.37 & 0.00 & 0.01 & 0.02 & 0.00 & 0.48 & 0.00 & 0.00 & 0.01 & 0.01 & 0.01 & 0.03 & 0.01 & 0.00 \\
\hline Nigeria & 17100 & 0.02 & 0.00 & 0.00 & 0.00 & 0.00 & 0.00 & 0.95 & 0.01 & 0.00 & 0.00 & 0.00 & 0.00 & 0.00 & 0.00 & 0.01 \\
\hline Norway & 47300 & 0.08 & 0.03 & 0.01 & 0.03 & 0.08 & 0.06 & 0.57 & 0.00 & 0.01 & 0.00 & 0.02 & 0.03 & 0.00 & 0.03 & 0.04 \\
\hline
\end{tabular}


Table A-1 cont'd

\begin{tabular}{|c|c|c|c|c|c|c|c|c|c|c|c|c|c|c|c|c|}
\hline Complainant & Total & $\begin{array}{l}50 \\
\vdots \\
\vdots \\
\vdots\end{array}$ & $\begin{array}{l}\exists \\
\vec{J}\end{array}$ & $\begin{array}{l}\text { בิ } \\
\text { บี } \\
\vdots\end{array}$ & $\begin{array}{c}\sum_{1}^{\tilde{J}} \\
\vdots\end{array}$ & 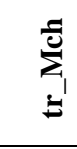 & 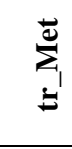 & $\sum_{\Xi}^{\Xi}$ & $\underset{\Xi}{\stackrel{P}{Z}}$ & $\begin{array}{l}\tilde{z} \\
\vdots \\
\xi\end{array}$ & $\begin{array}{l}\frac{\pi}{2} \\
\frac{a}{a}\end{array}$ & $\frac{\pi}{2}$ & $\vec{\omega}_{1}$ & $\stackrel{\not x}{\mid x}$ & $\begin{array}{l}z \\
5 \\
5\end{array}$ & $\frac{8}{3}$ \\
\hline Oman & 7760 & 0.02 & 0.00 & 0.00 & 0.01 & 0.01 & 0.00 & 0.91 & 0.00 & 0.01 & 0.00 & 0.00 & 0.00 & 0.02 & 0.00 & 0.00 \\
\hline Pakistan & 8520 & 0.12 & 0.00 & 0.00 & 0.04 & 0.01 & 0.01 & 0.02 & 0.08 & 0.01 & 0.00 & 0.01 & 0.00 & 0.69 & 0.00 & .00 \\
\hline Panama & 2620 & 0.26 & 0.01 & 0.01 & 0.03 & 0.13 & 0.02 & 0.08 & 0.04 & 0.02 & 0.08 & 0.01 & 0.01 & 0.10 & 0.19 & 0.02 \\
\hline Papua N Guinea & 1840 & 0.26 & 0.00 & 0.00 & 0.00 & 0.00 & 0.01 & 0.44 & 0.00 & 0.16 & 0.00 & 0.00 & 0.00 & 0.00 & 0.00 & 0.13 \\
\hline Paraguay & 1170 & 0.59 & 0.00 & 0.00 & 0.00 & 0.01 & 0.00 & 0.17 & 0.04 & 0.00 & 0.01 & 0.01 & 0.01 & 0.09 & 0.00 & 0.07 \\
\hline Peru & 5880 & 0.30 & 0.01 & 0.01 & 0.01 & 0.01 & 0.19 & 0.22 & 0.00 & 0.09 & 0.00 & 0.01 & 0.01 & 0.11 & 0.00 & 0.02 \\
\hline Philippines & 37100 & 0.07 & 0.00 & 0.00 & 0.04 & 0.72 & 0.01 & 0.02 & 0.01 & 0.01 & 0.00 & 0.01 & 0.00 & 0.08 & 0.01 & 0.01 \\
\hline Poland & 28500 & 0.08 & 0.03 & 0.01 & 0.10 & 0.21 & 0.05 & 0.09 & 0.01 & 0.01 & 0.01 & 0.04 & 0.08 & 0.10 & 0.11 & 0.07 \\
\hline Qatar & 9060 & 0.00 & 0.04 & 0.00 & 0.00 & 0.00 & 0.00 & 0.89 & 0.00 & 0.00 & 0.00 & 0.02 & 0.02 & 0.01 & 0.00 & 0.00 \\
\hline Romania & 10600 & 0.04 & 0.03 & 0.00 & 0.06 & 0.13 & 0.04 & 0.06 & 0.10 & 0.00 & 0.00 & 0.02 & 0.10 & 0.31 & 0.04 & 0.05 \\
\hline Rwanda & 85 & 0.38 & 0.01 & 0.00 & 0.00 & 0.01 & 0.01 & 0.46 & 0.01 & 0.09 & 0.00 & 0.00 & 0.01 & 0.01 & 0.00 & 0.00 \\
\hline St Kitts ar & 64 & 0.20 & 0.00 & 0.00 & 0.02 & 0.60 & 0.00 & 0.00 & 0.00 & 0.01 & 0.00 & 0.01 & 0.01 & 0.04 & 0.11 & 0.00 \\
\hline St Lucia & 90 & 0.62 & 0.00 & 0.01 & 0.01 & 0.13 & 0.00 & 0.03 & 0.00 & 0.00 & 0.00 & 0.00 & 0.00 & 0.11 & 0.05 & 0.04 \\
\hline St Vinc. \& Gren. & 193 & 0.37 & 0.00 & 0.00 & 0.00 & 0.02 & 0.00 & 0.01 & 0.00 & 0.03 & 0.00 & 0.00 & 0.01 & 0.00 & 0.55 & 0.01 \\
\hline Saudi Arabia & 60000 & 0.01 & 0.05 & 0.00 & 0.00 & 0.01 & 0.00 & 0.87 & 0.00 & 0.00 & 0.00 & 0.02 & 0.01 & 0.00 & 0.00 & 0.00 \\
\hline Senegal & 700 & 0.54 & 0.16 & 0.02 & 0.01 & 0.02 & 0.01 & 0.14 & 0.02 & 0.00 & 0.01 & 0.01 & 0.02 & 0.02 & 0.00 & 0.01 \\
\hline Sierra Leone & 143 & 0.11 & 0.01 & 0.01 & 0.14 & 0.09 & 0.01 & 0.02 & 0.02 & 0.28 & 0.00 & 0.01 & 0.00 & 0.02 & 0.26 & 0.02 \\
\hline Singapore & 80800 & 0.02 & 0.05 & 0.02 & 0.03 & 0.66 & 0.01 & 0.10 & 0.00 & 0.02 & 0.01 & 0.03 & 0.01 & 0.01 & 0.02 & 0.01 \\
\hline Slovak Republic & 11500 & 0.03 & 0.03 & 0.01 & 0.04 & 0.19 & 0.03 & 0.09 & 0.03 & 0.01 & 0.01 & 0.05 & 0.12 & 0.07 & 0.22 & 0.06 \\
\hline Slovenia & 8230 & 0.03 & 0.02 & 0.02 & 0.13 & 0.22 & 0.07 & 0.03 & 0.03 & 0.01 & 0.04 & 0.05 & 0.06 & 0.09 & 0.15 & 0.07 \\
\hline Solomon Islands & 134 & 0.52 & 0.00 & 0.00 & 0.01 & 0.01 & 0.00 & 0.00 & 0.00 & 0.00 & 0.00 & 0.00 & 0.00 & 0.00 & 0.00 & 0.45 \\
\hline South Africa & 36200 & 0.11 & 0.03 & 0.02 & 0.02 & 0.09 & 0.04 & 0.16 & 0.01 & 0.26 & 0.01 & 0.02 & 0.08 & 0.03 & 0.08 & 0.04 \\
\hline Sri Lanka & 4510 & 0.15 & 0.00 & 0.01 & 0.03 & 0.04 & 0.00 & 0.02 & 0.04 & 0.05 & 0.00 & 0.06 & 0.00 & 0.58 & 0.01 & 0.01 \\
\hline Suriname & 543 & 0.19 & 0.60 & 0.00 & 0.00 & 0.01 & 0.02 & 0.07 & 0.00 & 0.08 & 0.00 & 0.00 & 0.00 & 0.00 & 0.00 & 0.01 \\
\hline Swaziland & 391 & 0.44 & 0.01 & 0.01 & 0.03 & 0.09 & 0.01 & 0.01 & 0.00 & 0.02 & 0.09 & 0.01 & 0.01 & 0.19 & 0.01 & 0.08 \\
\hline Switzerlanc & 88800 & 0.03 & 0.08 & 0.04 & 0.15 & 0.26 & 0.03 & 0.02 & 0.00 & 0.18 & 0.10 & 0.03 & 0.02 & 0.02 & 0.02 & 0.02 \\
\hline Tanzania & 653 & 0.65 & 0.00 & 0.00 & 0.00 & 0.02 & 0.02 & 0.08 & 0.01 & 0.09 & 0.00 & 0.00 & 0.01 & 0.10 & 0.01 & 0.01 \\
\hline Thailand & 63000 & 0.16 & 0.01 & 0.01 & 0.06 & 0.41 & 0.01 & 0.04 & 0.03 & 0.03 & 0.00 & 0.08 & 0.02 & 0.08 & 0.03 & 0.02 \\
\hline Togo & 302 & 0.21 & 0.03 & 0.03 & 0.00 & 0.02 & 0.01 & 0.41 & 0.01 & 0.02 & 0.00 & 0.00 & 0.01 & 0.20 & 0.02 & 0.02 \\
\hline Trinidad & 3690 & 0.08 & 0.22 & 0.01 & 0.01 & 0.01 & 0.00 & 0.55 & 0.00 & 0.00 & 0.00 & 0.01 & 0.07 & 0.01 & 0.01 & 0.02 \\
\hline Tunisia & 6100 & 0.07 & 0.09 & 0.00 & 0.02 & 0.13 & 0.00 & 0.09 & 0.06 & 0.00 & 0.00 & 0.01 & 0.01 & 0.50 & 0.01 & 0.01 \\
\hline Turkey & 26200 & 0.13 & 0.01 & 0.01 & 0.02 & 0.13 & 0.02 & 0.07 & 0.02 & 0.02 & 0.00 & 0.03 & 0.08 & 0.40 & 0.07 & 0.01 \\
\hline US & 707000 & 0.08 & 0.04 & 0.03 & 0.08 & 0.39 & 0.02 & 0.03 & 0.01 & 0.02 & 0.03 & 0.05 & 0.02 & 0.03 & 0.14 & 0.03 \\
\hline Uganda & 396 & 0.87 & 0.00 & 0.00 & 0.00 & 0.01 & 0.01 & 0.01 & 0.03 & 0.01 & 0.00 & 0.00 & 0.01 & 0.03 & 0.01 & 0.00 \\
\hline United Arab Em. & 28100 & 0.04 & 0.01 & 0.01 & 0.01 & 0.04 & 0.03 & 0.74 & 0.00 & 0.05 & 0.01 & 0.01 & 0.01 & 0.03 & 0.01 & 0.00 \\
\hline Uruguay & 2520 & 0.48 & 0.02 & 0.02 & 0.01 & 0.02 & 0.01 & 0.02 & 0.10 & 0.02 & 0.04 & 0.05 & 0.01 & 0.11 & 0.05 & 0.05 \\
\hline Venezuela & 24500 & 0.02 & 0.03 & 0.00 & 0.00 & 0.01 & 0.04 & 0.82 & 0.00 & 0.00 & 0.00 & 0.01 & 0.04 & 0.00 & 0.01 & 0.00 \\
\hline Zambia & 685 & 0.13 & 0.00 & 0.01 & 0.00 & 0.02 & 0.65 & 0.06 & 0.00 & 0.03 & 0.00 & 0.00 & 0.01 & 0.09 & 0.01 & 0.00 \\
\hline Zimbabwe & 1770 & 0.51 & 0.01 & 0.01 & 0.01 & 0.02 & 0.07 & 0.08 & 0.02 & 0.04 & 0.00 & 0.01 & 0.10 & 0.10 & 0.01 & 0.02 \\
\hline
\end{tabular}

Note: Total trade includes all trade for which an HS 2-digit number has been reported. It is computed as an average over 1998-2002, as described in the main text. The remaining columns, which horizontally sum to unity, give the distribution of this trade across industry groups. 
Table A-2: Legal capacity and aid dependence (see note below)

\begin{tabular}{|c|c|c|c|}
\hline Country & Own legal capacity & Average partner legal capacity & Average aid dependence \\
\hline Albania & 27.75 & 96.80 & 2.38 \\
\hline Angola & 5.15 & 93.60 & 0.45 \\
\hline Antigua. \& Bar. & 48.11 & 88.45 & 0.18 \\
\hline Argentina & 51.96 & 70.52 & 0.00 \\
\hline Armenia & 27.70 & 89.56 & 1.22 \\
\hline Australia & 100.38 & 79.56 & 0.00 \\
\hline Bahrain & 55.09 & 71.79 & 0.00 \\
\hline Bangladesh & 33.17 & 99.46 & 0.14 \\
\hline Barbados & 68.88 & 65.10 & 0.03 \\
\hline Belize & 31.77 & 89.94 & 0.26 \\
\hline Benin & 34.65 & 51.17 & 0.31 \\
\hline Bolivia & 35.68 & 64.92 & 0.31 \\
\hline Botswana & 59.35 & 96.10 & 0.17 \\
\hline Brazil & 47.84 & 83.33 & 0.00 \\
\hline Brunei Daruss. & 53.24 & 84.38 & 0.00 \\
\hline Bulgaria & 34.60 & 85.87 & 0.00 \\
\hline Burkina Faso & 31.19 & 60.24 & 0.73 \\
\hline Burundi & 12.11 & 89.37 & 2.58 \\
\hline Cambodia & 24.20 & 101.27 & 0.74 \\
\hline Cameroon & 28.79 & 92.39 & 0.33 \\
\hline Canada & 106.58 & 102.50 & 0.00 \\
\hline Central Afr Rep & 13.58 & 94.89 & 2.50 \\
\hline Chad & 27.53 & 83.92 & 1.53 \\
\hline Chile & 79.36 & 81.73 & 0.00 \\
\hline China & 56.25 & 90.98 & 0.01 \\
\hline Colombia & 41.62 & 85.11 & 0.10 \\
\hline Congo & 11.30 & 80.74 & 0.05 \\
\hline Costa Rica & 56.64 & 91.92 & -0.09 \\
\hline Croatia & 49.77 & 88.20 & 0.07 \\
\hline Cuba & 35.78 & 83.71 & 0.02 \\
\hline Cyprus & 70.46 & 85.67 & 0.27 \\
\hline Czech Republic & 64.68 & 89.98 & 0.46 \\
\hline Côte d'Ivoire & 28.30 & 79.38 & 0.19 \\
\hline Dem. Rep. Congo & 0.00 & 95.92 & 0.80 \\
\hline Djibouti & 17.96 & 74.16 & 0.38 \\
\hline Dominica & 26.86 & 72.15 & 0.94 \\
\hline Dominican Rep. & 33.41 & 105.12 & 0.05 \\
\hline EC & 99.35 & 81.34 & 0.00 \\
\hline Ecuador & 22.15 & 84.43 & 0.11 \\
\hline Egypt & 46.04 & 87.40 & 0.19 \\
\hline El Salvador & 38.95 & 86.44 & 0.24 \\
\hline Estonia & 59.39 & 94.13 & 0.68 \\
\hline FYROM-Mac. & 31.06 & 90.74 & 1.65 \\
\hline Fiji & 36.87 & 98.96 & 0.31 \\
\hline Gabon & 27.09 & 95.20 & 0.08 \\
\hline
\end{tabular}


Table A-2 cont'd

\begin{tabular}{|c|c|}
\hline Country & Own legal capacity \\
\hline Gambia & 28.81 \\
\hline Georgia & 26.52 \\
\hline Ghana & 39.06 \\
\hline Grenada & 37.46 \\
\hline Guatemala & 33.87 \\
\hline Guinea & 29.46 \\
\hline Guinea-Bissau & 15.98 \\
\hline Guyana & 34.19 \\
\hline Haiti & 9.23 \\
\hline $\begin{array}{l}\text { Honduras } \\
\text { Hong Kong - }\end{array}$ & 30.77 \\
\hline China & 83.42 \\
\hline Hungary & 65.67 \\
\hline Iceland & 88.81 \\
\hline India & 47.30 \\
\hline Indonesia & 35.30 \\
\hline Israel & 74.96 \\
\hline Jamaica & 36.00 \\
\hline Japan & 86.86 \\
\hline Jordan & 51.73 \\
\hline Kenya & 24.80 \\
\hline Korea & 69.46 \\
\hline Kuwait & 47.88 \\
\hline Kyrgyz & \\
\hline Republic & 27.07 \\
\hline Latvia & 52.16 \\
\hline Lesotho & 33.06 \\
\hline Lithuania & 53.54 \\
\hline Macao - China & 60.95 \\
\hline Madagascar & 30.59 \\
\hline Malawi & 27.00 \\
\hline Malaysia & 67.33 \\
\hline Maldives & 46.71 \\
\hline Mali & 28.72 \\
\hline Malta & 59.49 \\
\hline Mauritania & 34.72 \\
\hline Mauritius & 54.22 \\
\hline Mexico & 56.89 \\
\hline Moldova & 23.04 \\
\hline Mongolia & 35.62 \\
\hline Morocco & 45.99 \\
\hline Mozambique & 31.03 \\
\hline Myanmar & 9.15 \\
\hline Namibia & 44.15 \\
\hline Nepal & 26.07 \\
\hline New Zealand & 91.65 \\
\hline Nicaragua & 26.34 \\
\hline Niger & 18.89 \\
\hline Nigeria & 17.68 \\
\hline Norway & 97.17 \\
\hline
\end{tabular}

\section{Average partner legal capacity}

86.44

74.06

90.11

78.23

86.47

90.53

56.33

93.59

105.95

99.50

83.97

93.47

97.19

84.30

84.60

94.99

97.42

87.23

67.31

74.64

83.50

83.61

82.12

89.72

105.21

89.18

99.70

96.16

84.21

91.04

88.40

71.06

94.11

80.43

96.02

103.50

86.33

76.85

92.46

78.52

75.95

94.57

80.13

87.23

91.35

80.04

87.87

97.09
Average aid dependence

1.27

0.49

0.60

0.09

0.18

0.90

0.98

0.97

2.04

1.44

0.00

0.39

0.00

0.01

0.15

0.31

0.04

0.00

0.41

0.19

0.00

0.00

0.83

0.52

0.33

0.46

0.00

1.16

2.42

0.01

0.08

0.54

0.05

6.78

0.27

0.00

0.93

0.95

0.47

1.77

0.02

1.13

0.20

0.00

1.29

0.90

0.03

0.00 
Table A-2 cont'd

\begin{tabular}{|c|c|c|c|}
\hline Country & Own legal capacity & Average partner legal capacity & Average aid dependence \\
\hline Oman & 64.30 & 71.51 & 0.01 \\
\hline Pakistan & 31.41 & 86.55 & 0.10 \\
\hline Panama & 42.07 & 62.59 & 0.00 \\
\hline Papua New Guinea & 26.43 & 89.09 & 2.95 \\
\hline Paraguay & 15.98 & 62.87 & 0.04 \\
\hline Peru & 41.36 & 85.05 & 0.12 \\
\hline Philippines & 48.46 & 92.25 & 0.10 \\
\hline Poland & 65.70 & 92.64 & 0.32 \\
\hline Qatar & 60.29 & 82.17 & 0.00 \\
\hline Romania & 32.40 & 89.22 & 0.66 \\
\hline Rwanda & 27.67 & 75.00 & 1.27 \\
\hline Saint Kitts and Nevis & 33.46 & 102.09 & 0.09 \\
\hline St Lucia & 37.31 & 89.47 & 0.70 \\
\hline St Vincent \& the Gren. & 33.16 & 85.46 & 0.78 \\
\hline Saudi Arabia & 43.97 & 83.75 & 0.00 \\
\hline Senegal & 41.51 & 73.24 & 0.81 \\
\hline Sierra Leone & 13.54 & 87.61 & 2.70 \\
\hline Singapore & 108.04 & 81.20 & 0.00 \\
\hline Slovak Republic & 50.67 & 87.31 & 0.53 \\
\hline Slovenia & 62.90 & 88.40 & 0.27 \\
\hline Solomon Islands & 14.42 & 72.10 & 1.31 \\
\hline South Africa & 57.81 & 78.14 & 0.05 \\
\hline Sri Lanka & 38.24 & 96.08 & 0.05 \\
\hline Suriname & 36.32 & 94.57 & 0.12 \\
\hline Swaziland & 26.25 & 80.22 & 0.31 \\
\hline Switzerland & 109.74 & 90.15 & 0.00 \\
\hline Tanzania & 31.37 & 75.88 & 0.50 \\
\hline Thailand & 51.98 & 88.92 & 0.06 \\
\hline Togo & 16.34 & 57.78 & 0.08 \\
\hline Trinidad and Tobago & 54.61 & 85.02 & 0.01 \\
\hline Tunisia & 63.40 & 94.88 & 0.65 \\
\hline Turkey & 45.86 & 91.81 & 0.05 \\
\hline US & 107.45 & 82.67 & 0.00 \\
\hline Uganda & 35.06 & 88.81 & 0.72 \\
\hline United Arab Emirates & 61.02 & 77.03 & 0.00 \\
\hline Uruguay & 57.95 & 67.72 & 0.00 \\
\hline Venezuela & 23.98 & 89.27 & 0.00 \\
\hline Zambia & 27.24 & 69.67 & 0.74 \\
\hline Zimbabwe & 20.89 & 77.87 & 0.11 \\
\hline
\end{tabular}

Note: "Own legal capacity" is computed as described in the main text. "Average partner legal capacity" of a country $i$ is each of its trade partners' legal capacity weighted with the partner's share of total exports of country i. "Average aid dependence" is for a country i the weighted average of its net recepits of aid as a fraction of its GDP, where the weights are each donor's share of the total exports from $i$. 


\section{Table A-3 The definition of the 15 industry groups in terms of the Harmonized System nomenclature}

Agr:

SECTION I (HS-1 - HS-5): Live animals, animal products

SECTION II (HS-6 - HS-14): Vegetable products

SECTION III (HS-15) Animal or vegetable fats and oils and their cleavage products; prepared edible fats; animal or vegetable waxes

SECTION IV (HS-16 - HS-24): Prepared foodstuffs; beverages, spirits and vinegar; tobacco and manufactured tobacco substitutes

\section{Mat1:}

SECTION V (HS 25-27): Mineral products

SECTION XIII (68-70): Articles of stone, plaster, cement, asbestos, mica or similar materials; ceramic products; glass and glassware

\section{Ch1:}

HS-28 Inorganic chemicals; organic or inorganic compounds of precious metals, of rareearth metals, of radioactive elements or of isotopes

HS-29 Organic chemicals

HS-31 Fertilisers

\section{Pha:}

HS-30 Pharmaceutical products

HS-33 33 Essential oils and resinoids; perfumery, cosmetic or toilet preparations.

\section{Ch2:}

HS-32 Tanning or dyeing extracts; tannins and their derivatives; dyes, pigments and other colouring matter; paints and varnishes; putty and other mastics; inks.

HS-34 Soap, organic surface-active agents, washing preparations, lubricating preparations, artificial waxes, prepared waxes, polishing or scouring preparations, candles and similar articles, modelling pastes, "dental waxes" and dental preparations with a basis of plaster. HS-35 Albuminoidal substances; modified starches; glues; enzymes.

HS-36 Explosives; pyrotechnic products; matches; pyrophoric alloys; certain combustible preparations.

HS-37 Photographic or cinematographic goods.

HS-38 Miscellaneous chemical products.

\section{Pla:}

SECTION VII (HS-39 - HS-40): Plastics and articles thereof; rubber and articles thereof

\section{Mat2:}

SECTION VIII (HS-41 - HS-43): Raw hides and skins, leather, furskins and articles thereof; saddlery and harness; travel goods, handbags and similar containers; articles of animal gut (other than silk-worm gut)

SECTION XII (HS-64 - HS-67 except for HS-65): Footwear, headgear, umbrellas, sun umbrellas, walking-sticks, seat-sticks, whips, riding-crops and parts thereof; prepared feathers and articles made therewith; artificial flowers; articles of human hair 


\section{Woo:}

SECTION IX (HS-44 - HS 46): Wood and articles of wood; wood charcoal; cork and articles of cork; manufactures of straw, of esparto or of other plaiting materials; basketware and wickerwork

HS-47 Pulp of wood or of other fibrous cellulosic material; recovered (waste and scrap) paper or paperboard.

HS-48 Paper and paperboard; articles of paper pulp, of paper or of paperboard.

\section{Txl:}

SECTION XI (HS-50 - HS-63, HS-65): Textiles and textile articles

HS-65 Headgear and parts thereof.

Stl:

HS-72 Iron and steel.

HS-73 Articles of iron or steel.

Met:

SECTION XV (HS-74 - HS-83 except for HS-72, HS-73): Base metals and articles of base metal

Mch:

SECTION XVI (HS-84 - HS-85): Machinery and mechanical appliances; electrical equipment; parts thereof; sound recorders and reproducers, television image and sound recorders and reproducers, and parts and accessories of such articles

Vhl:

SECTION XVII (HS-86 - HS-89): Vehicles, aircraft, vessels and associated transport equipment

\section{Man:}

SECTION XVIII (HS-90 - HS-92): Optical, photographic, cinematographic, measuring, checking, precision, medical or surgical instruments and apparatus; clocks and watches; musical instruments; parts and accessories thereof;

SECTION XIX (HS-93): Arms and ammunition; parts and accessories thereof; SECTION XX (HS-94 - HS-96): Miscellaneous manufactured articles

\section{Oth:}

HS-49 Printed books, newspapers, pictures and other products of the printing industry; manuscripts, typescripts and plans.

SECTION XIV (HS-71): Natural or cultured pearls, precious or semi-precious stones, precious metals, metals clad with precious metal and articles thereof; imitation jewellery; coin

SECTION XXI (HS-97): works of art, collectors' pieces and antiques. 


\section{Table A-4: The DS disputes that form the basis for the set of industry-specific bilateral disputes}

\section{DS no Official title of dispute}

1 Prohibition of imports of polyethylene and polypropylene

2 Standards for reformulated and conventional gasoline

$3 \quad$ Measures concerning the testing and inspection of agricultural products

$4 \quad$ Standards for reformulated and conventional gasoline

$5 \quad$ Measures concerning the shelf-life of products

Imposition of import duties on automobiles from Japan under sections 301 and 304 of the trade act of 1974

Trade description of scallops

Taxes on alcoholic beverages

Duties on imports of cereals

Taxes on alcoholic beverages

Taxes on alcoholic beverages

Trade description of scallops

Duties on imports of grains

Trade description of scallops

Measures affecting the purchase of telecommunications equipment

Regime for importation, sale and distribution of bananas

Duties on imports of rice

Measures affecting importation of salmon

Import regime for automobiles

Measures concerning the bottled water

Measures concerning the importation of salomonids

Measures affecting desiccated coconut

Anti-dumping investigation in respect of imports of certain oil country tubular goods (OCTG)

Restrictions on imports of cotton and man-made fibre underwear

Implementation of the Uruguay Round commitments concerning rice

Measures concerning meat and meat products (hormones)

Regime for the importation, sale and distribution of bananas

Measures concerning sound recordings

Restrictions on imports of textile and clothing products

Countervailing duties on imports of desiccated coconut and coconut milk powder from Sri Lanka

Certain measures concerning periodicals

Measures affecting imports of women's and girls' woolcoats

Measures affecting imports of woven wool shirts and blouses

Restrictions on imports of textile and clothing products

Patent protection for pharmaceutical and agricultural chemical products

Laws, regulations and practices in the telecommunications procurement sector

Measures concerning inspection of agricultural products

Measures concerning sound recordings

Measures affecting consumer photographic film and paper

Restrictions on imports of textile and clothing products

Measures affecting livestock and meat (hormones)

Anti-dumping investigation regarding imports of fresh or chilled tomatoes from Mexico

Patent protection for pharmaceutical and agricultural chemical products

Certain automotive investment measures

Certain measures affecting trade and investment in the automotive sector 


\section{Table A-4 cont'd}

54 Certain measures affecting the automobile industry

55 Certain measures affecting the automobile industry

56 Measures affecting imports of footwear, textiles, apparel and other items

57 Textile, clothing and footwear import credit scheme

58 Import prohibition of certain shrimp and shrimp products

59 Certain measures affecting the automobile industry

60 Anti-dumping investigation regarding portland cement from Mexico

61 Import prohibition of certain shrimp and shrimp products

62 Customs classification of certain computer equipment

63 Anti-dumping measures on imports of solid urea from the former German Democratic Republic

64 Certain measures affecting the automobile industry

65 Certain measures affecting trade and investment in the automotive sector

66 Measures affecting imports of pork

67 Customs classification of certain computer equipment

68 Customs classification of certain computer equipment

69 Measures affecting importation of certain poultry products

72 Measures affecting butter products

73 Procurement of a navigation satellite

74 Measures affecting pork and poultry

75 Taxes on alcoholic beverages

76 Measures affecting agricultural products

77 Measures affecting textiles, clothing and footwear

78 Safeguard measure against imports of broom and corn brooms

79 Patent protection for pharmaceutical and agricultural chemical products

81 Certain measures affecting trade and investment in the automotive sector

84 Taxes on alcoholic beverages

85 Measures affecting textiles and apparel products

87 Taxes on alcoholic beverages

89 Imposition of anti-dumping duties on imports of colour television receivers from Korea

97 Countervailing duty investigation of imports of salmon from Chile

98 Definitive safeguard measure on imports of certain dairy products

99 Anti-dumping duty on dynamic random access memory semiconductors (drams) ... from Korea

100 Measures affecting imports of poultry products

101 Anti-dumping investigation of high-fructose corn syrup (HFCS) from the United States

102 Measures affecting pork and poultry

105 Regime for the importation, sale and distribution of bananas

106 Subsidies provided to producers and exporters of automotive leather

107 Export measures affecting hides and skins

109 Taxes on alcoholic beverages

110 Taxes on alcoholic beverages

111 Tariff rate quota for imports of groundnuts

112 Countervailing duty investigation against imports of buses from Brazil

114 Patent protection of pharmaceutical products

119 Anti-dumping measures on imports of coated woodfree paper sheets

121 Safeguard measures on imports of footwear

122 Anti-dumping duties on angles, shapes and sections of iron or non-alloysteel and H-beams from Poland

123 Safeguard measures on imports of footwear

126 Subsidies provided to producers and exporters of automotive leather

132 Anti-dumping investigation of high-fructose corn syrup (HFCS) from the United States 


\section{Table A-4 cont'd}

133 Measures concerning the importation of dairy products and the transit of cattle

134 Restrictions on certain import duties on rice

135 Measures affecting asbestos and products containing asbestos

137 Measures affecting imports of wood of conifers from Canada

138 Imposition of CVDs on certain hot-rolled lead and bismuth carbon steel products originating in the UK

139 Certain automotive industry measures

140 Anti-dumping investigations regarding unbleached cotton fabrics from India

141 Anti-dumping duties on imports of cotton-type bed-linen from India

142 Certain measures affecting the automotive industry

143 Measure affecting import duty on wheat from Hungary

144 Certain measures affecting the import of cattle, swine and grain from Canada

145 Countervailing duties on imports of wheat gluten from the EC

146 Measures affecting the automotive sector

147 Tariff quotas and subsidies affecting leather

148 Measure affecting import duty on wheat from Hungary

151 Measures affecting textiles and apparel products (II)

153 Patent protection on pharmaceutical and agricultural chemical products

154 Measures affecting differential and favourable treatment of coffee

156 Definitive anti-dumping measure on grey portland cement from Mexico

157 Definitive anti-dumping measures on imports of drill bits from Italy

158 Regime for the importation, sale and distribution of bananas

159 Safeguard measure on imports of steel products from the Czech Republic

161 Measures affecting imports of fresh, chilled and frozen beef

164 Measures affecting imports of footwear

165 Import measures on certain products from the EC

166 Definitive safeguard measures on imports of wheat gluten from the EC

167 Countervailing duty investigation with respect to live cattle from Canada

168 Anti-dumping duties on certain pharmaceutical products from India

169 Measures affecting imports of fresh, chilled and frozen beef

171 Patent protection for pharmaceuticals and test data protection for agricultural chemicals

172 Measures relating to the development of a flight management system

173 Measures relating to the development of a flight management system

175 Measures affecting trade and investment in the motor vehicle sector

177 Safeguard measure on imports of fresh, chilled and frozen lamb from New Zealand

178 Safeguard measure on imports of lamb meat from Australia

179 Anti-dumping measures on stainless steel plate in coils and stainless steel sheet and strip from Korea

180 Reclassification on certain sugar syrups

181 Safeguard measure on imports of plain polyester filaments from Thailand

182 Ecuador - Provisional anti-dumping measure on cement from Mexico

184 Anti-dumping measures on certain hot-rolled steel products from Japan

185 Certain measures affecting imports of pasta from Costa Rica

187 Provisional anti-dumping measure on imports of macaroni and spaghetti from Costa Rica

189 Definitive anti-dumping measures on carton-board imports from Germany .... ceramic floor tiles from Italy

190 Transitional safeguard measures on certain imports of woven fabrics of cotton ... originating in Brazil

191 Definitive anti-dumping measure on cement from Mexico

192 Transitional safeguard measure on combed cotton yarn from Pakistan

193 Measures affecting the transit and importation of swordfish

195 Measures affecting trade and investment in the motor vehicle sector

202 Definitive safeguard measures on imports of circular welded carbon quality line pipe from Korea

203 Measures affecting trade in live swine 


\section{Table A-4 cont'd}

205 Import Prohibition on canned tuna with soybean oil

206 Anti-dumping and countervailing measures on steel plate from India

207 Price band system and safeguard measures relating to certain agricultural products

208 Anti-dumping duty on steel and iron pipe fittings

209 Measures affecting soluble coffee

210 Administration of measures establishing customs duties for rice

211 Definitive anti-dumping measures on steel rebar from Turkey

212 Countervailing measures concerning certain products from the EC

213 Countervailing duties on certain corrosion-resistant carbon steel flat products from Germany

214 Definitive safeguard measures on imports of steel wire rod and circular welded carbon quality line pipe

215 Anti-dumping measures regarding polypropylene resins from Korea

216 Provisional anti-dumping measure on electric transformers

218 Countervailing duties on certain carbon steel products from Brazil

219 Anti-dumping duties on malleable cast iron tube or pipe fittings from Brazil

220 Price band system and safeguard measures relating to certain agricultural products

223 Tariff-rate quota on corn gluten feed from the US

225 Anti-dumping duties on seamless pipe from Italy

226 Provisional safeguard measure on mixtures of edible oils

227 Taxes on cigarettes

228 Safeguard Measures on Sugar

229 Anti-Dumping Duties on Jute Bags from India

230 Safeguard Measures and Modification of Schedules Regarding Sugar

231 Trade Description of Sardines

232 Measures Affecting the Import of Matches

233 Measures Affecting the Import of Pharmaceutical Products

235 Safeguard Measure on Imports of Sugar

236 Preliminary Determinations with Respect to Certain Softwood Lumber from Canada

237 Certain Import Procedures for Fresh Fruit

238 Definitive Safeguard Measures on Imports of Preserved Peaches

240 Import Prohibition on Wheat and Wheat Flour

241 Definitive Anti-Dumping Duties on Poultry from Brazil

243 Rules of origin for textiles and apparel products

244 Sunset review of anti-dumping duties on corrosion-resistant carbon steel flat products from Japan

245 Measures affecting the importation of apples

247 Provisional anti-dumping measure on imports of certain softwood lumber from Canada

248 Definitive safeguard measures on imports of certain steel products

249 Definitive safeguard measures on imports of certain steel products

250 Equalizing excise tax imposed by Florida on processed orange and grapefruit Products

251 Definitive safeguard measures on imports of certain steel products

252 Definitive safeguard measures on imports of certain steel products

253 Definitive safeguard measures on imports of certain steel products

254 Definitive safeguard measures on imports of certain steel products

255 Tax treatment on certain imported products

256 Import ban on pet food from Hungary

257 Final countervailing duty determination with respect to certain softwood lumber from Canada

258 Definitive safeguard measures on imports of certain steel products

259 Definitive safeguard measures on imports of certain steel products

260 Provisional safeguard measures on imports of certain steel products

262 Sunset reviews of anti-dumping and CVDs on certain steel products from France and Germany

263 Measures affecting imports of wine

264 Final dumping determination on softwood lumber from Canada

267 Subsidies on upland Cotton

268 Sunset reviews of anti-dumping measures on oil country tubular goods from Argentina

269 Customs classification of frozen boneless chicken cuts 


\section{Table A-4 cont'd}

270 Certain measures affecting the importation of fresh fruit and vegetables

271 Certain measures affecting the importation of fresh pineapple

272 Provisional anti-dumping duties on vegetable oils from Argentina

273 Measures affecting trade in commercial vessels

274 Definitive safeguard measures on imports of certain steel products

275 Import licensing measures on certain agricultural products

277 Investigation of the International Trade Commission in softwood lumber from Canada

278 Definitive safeguard measure on imports of fructose

279 Import restrictions maintained under the export and import policy 2002-2007

280 Countervailing duties on steel plate from Mexico

281 Anti-dumping measures on cement from Mexico

283 Export subsidies on sugar

284 Certain measures preventing the importation of black beans from Nicaragua

286 Customs classification of frozen boneless chicken cuts

287 Quarantine regime for imports

288 Definitive anti-dumping measures on blanketing from Turkey

289 Additional duty on imports of pig-meat from Poland

295 Definitive anti-dumping measures on beef and rice

296 CVD investigation on dynamic random access memory semiconductors (DRAMS) from Korea

297 Measure affecting imports of live animals and meat products

299 Countervailing measures on dynamic random access memory chips from Korea

300 Measures affecting the importation of cigarettes

301 Measures affecting trade in commercial vessels

302 Measures affecting the importation and internal sale of cigarettes

303 Definitive safeguard measure on imports of medium density fibreboard

304 Anti-dumping measures on imports of certain products from the EC and/or member states

305 Measures affecting imports of textile and apparel products

306 Anti-dumping measure on batteries from Bangladesh

307 Aid for commercial vessels

308 Tax measures on soft drinks and other beverages

309 Value-added Tax on Integrated Circuits

310 Determination of the International Trade Commission in Hard Red Spring Wheat from Canada

311 Reviews of countervailing duty on softwood lumber from Canada

312 Anti-dumping duties on imports of certain paper from Indonesia

313 Anti-dumping duties on certain flat rolled iron or non-alloy steel products from India

314 Provisional countervailing measures on olive oil from EC

316 Measures Affecting Trade in Large Civil Aircraft

317 Measures Affecting Trade in Large Civil Aircraft

323 Import quotas on dried laver and seasoned laver

324 Provisional anti-dumping measures on shrimp from Thailand

325 Anti-dumping determinations regarding stainless steel from Mexico

326 Definitive safeguard measure on salmon

327 Anti-dumping duties on matches from Pakistan

328 Definitive Safeguard Measure on Salmon

329 Tariff Classification of Certain Milk Products

330 Countervailing Duties on Olive oil, Wheat Gluten and Peaches

331 Anti-dumping Duties on Steel Pipes and Tubes from Guatemala

332 Measures Affecting Imports of Retreaded Tires

334 Measures Affecting the Importation of Rice

335 Anti-dumping measure on shrimp from Ecuador

336 Countervailing Duties on Dynamic Random Access Memories from Korea 


\section{Table A-4 cont'd}

337 Anti-Dumping Measure on Farmed Salmon from Norway

338 Provisional Anti-dumping and Countervailing Duties on grain corn from the US

339 Measures affecting imports of automobile parts

340 Measures affecting imports of automobile parts

341 Definitive countervailing measures on olive oil from the EC

342 Measures affecting imports of automobile parts

343 Measures relating to shrimp from Thailand

345 Customs bond directive for merchandise subject to Anti-Dumping/Countervailing Duties

347 Measures Affecting Trade in Large Civil Aircraft (Second Complaint)

348 Customs Measures on Importation of Certain Products from Panama

349 Measures Affecting the Tariff Quota for Fresh or Chilled Garlic

351 Provisional Safeguard Measure on Certain Milk Products 
Table A-5: The DS disputes that form the basis for the set of industry-specific bilateral disputes

\begin{tabular}{|c|c|c|c|}
\hline DS no & Complainants & Respondent & Industry groups \\
\hline 1 & Singapore & Malaysia & Pla \\
\hline 2 & Venezuela & US & Mt1 \\
\hline 3 & US & Korea & Agr \\
\hline 4 & Brazil & US & Mt1 \\
\hline 5 & US & Korea & Agr, Ch2, Man, Met, Oth, Pha, Pla \\
\hline 6 & Japan & US & Vhl \\
\hline 7 & Canada & EC & Agr \\
\hline 8 & EC & Japan & Agr \\
\hline 9 & Canada & EC & Agr \\
\hline 10 & Canada & Japan & Agr \\
\hline 11 & US & Japan & Agr \\
\hline 12 & Peru & $\mathrm{EC}$ & Agr \\
\hline 13 & US & EC & Agr \\
\hline 14 & Chile & EC & Agr \\
\hline 15 & EC & Japan & Agr, Mch \\
\hline 16 & Guatemala, Honduras, Mexico, US & $\mathrm{EC}$ & Agr \\
\hline 17 & Thailand & EC & Agr \\
\hline 18 & Canada & Australia & Agr \\
\hline 19 & India & Poland & Vhl \\
\hline 20 & Canada & Korea & Agr \\
\hline 21 & US & Australia & Agr \\
\hline 22 & Philippines & Brazil & Agr \\
\hline 23 & Mexico & Venezuela & Stl \\
\hline 24 & Costa Rica & US & Txl \\
\hline 25 & Uruguay & EC & Agr \\
\hline 26 & US & EC & Agr \\
\hline 27 & Ecuador, Guatemala, Honduras, Mexico, US & EC & Agr \\
\hline 28 & US & Japan & Mch \\
\hline 29 & Hong Kong - China & Turkey & Txl \\
\hline 30 & Sri Lanka & Brazil & Agr \\
\hline 31 & US & Canada & Oth \\
\hline 32 & India & US & Txl \\
\hline 33 & India & US & Txl \\
\hline 34 & India & Turkey & Txl \\
\hline 36 & US & Pakistan & Ch1, Pha \\
\hline 40 & EC & Korea & Mch \\
\hline 41 & US & Korea & Agr \\
\hline 42 & $\mathrm{EC}$ & Japan & Mch \\
\hline 44 & US & Japan & Ch2 \\
\hline 47 & Thailand & Turkey & Txl \\
\hline 48 & Canada & EC & Agr \\
\hline 49 & Mexico & US & Agr \\
\hline 50 & US & India & Ch1, Pha \\
\hline 51 & Japan & Brazil & Vhl \\
\hline 52 & US & Brazil & Vhl \\
\hline
\end{tabular}


Table A-5 cont'd

54 EC

55 Japan

56 US

57 US

58 India, Malaysia, Pakistan, Thailand

59 US

60 Mexico

61 Philippines

62 US

63 EC

64 Japan

65 US

66 EC

67 US

68 US

69 Brazil

72 New Zealand

73 EC

74 US

75 EC

76 US

77 EC

78 Colombia

79 EC

81 EC

84 US

85 EC

87 EC

89 Korea

97 Chile

98 EC

99 Korea

100 EC

101 US

102 US

105 Panama

106 US

107 EC

109 US

110 EC

111 Argentina

112 Brazil

114 EC

119 Switzerland

121 EC

122 Poland

123 Indonesia

126 US

132 US
Indonesia

Vhl

Indonesia

Vhl

Argentina

Australia

US

Indonesia

Guatemala

US

EC

US

Indonesia

Brazil

Japan

United Kingdom

Ireland

EC

EC

Japan

Philippines

Korea

Japan

Argentina

US

India

Brazil

Korea

US

Chile

US

US

Korea

US

US

Mexico

Philippines

EC

Australia

Pakistan

Chile

Chile

US

Peru

Canada

Australia

Argentina

Thailand

Argentina

Australia

Mexico
Mt2, Txl

Mt2

Agr

Vhl

Mt1

Agr

Mch

Ch1

Vhl

Vhl

Agr

Mch

Mch

Agr

Agr

Vhl

Agr

Agr

Agr

Mt2, Txl

Man

Ch1, Pha

Vhl

Agr

Txl

Agr

Mch

Agr

Agr

Mch

Agr

Agr

Agr

Agr

Mt2

Mt2

Agr

Agr

Agr

Vhl

Pha

Woo

Mt2

Stl

Mt2

Mt2

Agr 
Table A-5 cont'd

\begin{tabular}{|c|c|c|c|}
\hline 133 & Switzerland & Slovak Republic & Agr \\
\hline 134 & India & $\mathrm{EC}$ & Agr \\
\hline 135 & Canada & $\mathrm{EC}$ & Mt1 \\
\hline 137 & Canada & EC & Woo \\
\hline 138 & $\mathrm{EC}$ & US & Stl \\
\hline 139 & Japan & Canada & Vhl \\
\hline 140 & India & $\mathrm{EC}$ & Txl \\
\hline 141 & India & $\mathrm{EC}$ & Txl \\
\hline 142 & EC & Canada & Vhl \\
\hline 143 & Hungary & Slovak Republic & Agr \\
\hline 144 & Canada & US & Agr \\
\hline 145 & $\mathrm{EC}$ & Argentina & Agr \\
\hline 146 & $\mathrm{EC}$ & India & Vhl \\
\hline 147 & $\mathrm{EC}$ & Japan & Mt2 \\
\hline 148 & Hungary & Czech Republic & Agr \\
\hline 151 & $\mathrm{EC}$ & US & Txl \\
\hline 153 & Canada & $\mathrm{EC}$ & Ch1, Pha \\
\hline 154 & Brazil & EC & Agr \\
\hline 156 & Mexico & Guatemala & Mt1 \\
\hline 157 & EC & Argentina & Met \\
\hline 158 & Honduras, Mexico, Guatemala, Panama, US & $\mathrm{EC}$ & Agr \\
\hline 159 & Czech Republic & Hungary & Stl \\
\hline 161 & US & Korea & Agr \\
\hline 164 & US & Argentina & Mt2 \\
\hline 165 & EC & US & $\begin{array}{l}\text { Agr, Ch2, Mch, Mt2, } \\
\text { Oth, Pha, Pla, Txl, Woo }\end{array}$ \\
\hline 166 & EC & US & Agr \\
\hline 167 & Canada & US & Agr \\
\hline 168 & India & South Africa & Ch1, Pha \\
\hline 169 & Australia & Korea & Agr \\
\hline 171 & US & Argentina & Ch1, Pha \\
\hline 172 & US & $\mathrm{EC}$ & Vhl \\
\hline 173 & US & France & Vhl \\
\hline 175 & US & India & Vhl \\
\hline 177 & New Zealand & US & Agr \\
\hline 178 & Australia & US & Agr \\
\hline 179 & Korea & US & Stl \\
\hline 180 & Canada & US & Agr \\
\hline 181 & Thailand & Colombia & Txl \\
\hline 182 & Mexico & Ecuador & Ch1, Mt1 \\
\hline 184 & Japan & US & Stl \\
\hline 185 & Costa Rica & Trinidad and Tobago & Agr \\
\hline 187 & Costa Rica & Trinidad and Tobago & Agr \\
\hline 189 & $\mathrm{EC}$ & Argentina & Mt1, Woo \\
\hline 190 & Brazil & Argentina & Txl \\
\hline 191 & Mexico & Ecuador & Mt1 \\
\hline 192 & Pakistan & US & Txl \\
\hline 193 & $\mathrm{EC}$ & Chile & Agr \\
\hline 195 & US & Philippines & Vhl \\
\hline 202 & Korea & US & Stl \\
\hline
\end{tabular}


Table A-5 cont'd

203 US

205 Thailand

206 India

207 Argentina

208 Brazil

209 Brazil

210 US

211 Turkey

212 EC

213 EC

214 EC

215 Korea

216 Brazil

218 Brazil

219 Brazil

220 Guatemala

223 US

225 EC

226 Argentina

227 Chile

228 Colombia

229 India

230 Colombia

231 Peru

232 Chile

233 India

235 Poland

236 Canada

237 Ecuador

238 Chile

240 Hungary

241 Brazil

243 India

244 Japan

245 US

247 Canada

248 EC

249 Japan

250 Brazil

251 Korea

252 China

253 Switzerland

254 Norway

255 Chile

256 Hungary

257 Canada

258 New Zealand

259 Brazil

260 US

262 EC

263 Argentina

264 Canada

267 Brazil

268 Argentina
Mexico

Egypt

US

Chile

Turkey

EC

EC

Egypt

US

US

US

Philippines

Mexico

US

EC

Chile

EC

US

Chile

Peru

Chile

Brazil

Chile

EC

Mexico

Argentina

Slovak Republic

US

Turkey

Argentina

Romania

Argentina

US

US

Japan

US

US

US

US

US

US

US

US

Peru

Turkey

US

US

US

EC

US

EC

US

US

US
Agr

Agr

Stl

Agr

Stl

Agr

Agr

Stl

Agr, Stl

Stl

Stl

Pla

Mch

Stl

Stl

Agr

Agr

Stl

Agr

Agr

Agr

Txl

Agr

Agr

Ch2

Pha

Agr

Woo

Agr

Agr

Agr

Agr

Txl

Stl

Agr

Woo

Mch, Stl

Mch, Stl

Agr

Mch, Stl

Mch, Stl

Mch, Stl

Mch, Stl

Agr

Agr

Woo

Mch, Stl

Mch, Stl

Stl

Stl

Agr

Woo

Txl

Stl 
Table A-5 cont'd

270 Philippines

271 Philippines

272 Argentina

273 EC

274 Chinese Taipei

275 US

277 Canada

278 Argentina

279 EC

280 Mexico

281 Mexico

283 Thailand

284 Nicaragua

286 Thailand

287 EC

288 Turkey

289 Poland

295 US

296 Korea

297 Hungary

299 Korea

300 Honduras

301 Korea

302 Honduras

303 Chile

304 EC

305 US

306 Bangladesh

307 Korea

308 US

309 US

310 Canada

311 Canada

312 Indonesia

313 India

314 EC

316 US

317 EC

323 Korea

324 Thailand

325 Mexico

326 Chile

327 Pakistan

328 Norway
Australia

Australia

Peru

Korea

US

Venezuela

US

Chile

India

US

US

EC

Mexico

EC

Australia

South Africa

Czech Republic

Mexico

US

Croatia

EC

Dominican Republic

EC

Dominican Republic

Ecuador

India

Egypt

India

EC

Mexico

China

US

US

Korea

EC

Mexico

EC

US

Japan

US

US

EC

Egypt

EC
Agr

Agr

Agr

Vhl

Mch, Stl

Agr

Woo

Agr

Agr, Ch1, Ch2, Mch,

Mt1, Oth, Pha, Stl, Vhl, Woo

Stl

Mt1

Agr

Agr

Agr

Agr

Txl

Agr

Agr

Mch

Agr

Mch

Agr

Vhl

Agr

Woo

Ch1, Ch2, Pla, Stl, Txl, Woo

Txl

Mch

Vhl

Agr

Mch

Agr

Woo

Woo

Stl

Agr

Vhl

Vhl

Agr

Agr

Stl

Agr

Ch2

Agr 
Table A-5 cont'd

329 Mexico

330 EC

331 Guatemala

332 EC

334 US

335 Ecuador

336 Korea

337 Norway

338 US

339 EC

340 US

341 EC

342 Canada

343 Thailand

345 India

347 US

348 Panama

349 Argentina

351 Argentina
Panama

Argentina

Mexico

Brazil

Turkey

US

Japan

EC

Canada

China

China

Mexico

China

US

US

EC

Colombia

EC

Chile
Agr

Agr

Stl

Vhl

Agr

Agr

Mch

Agr

Agr

Vhl

Vhl

Agr

Vhl

Agr

Agr

Vhl

Mt2

Agr

Agr 


\section{Table A-5 cont'd}

337 Anti-Dumping Measure on Farmed Salmon from Norway

338 Provisional Anti-dumping and Countervailing Duties on grain corn from the US

339 Measures affecting imports of automobile parts

340 Measures affecting imports of automobile parts

341 Definitive countervailing measures on olive oil from the EC

342 Measures affecting imports of automobile parts

343 Measures relating to shrimp from Thailand

345 Customs bond directive for merchandise subject to Anti-Dumping/Countervailing Duties

347 Measures Affecting Trade in Large Civil Aircraft (Second Complaint)

348 Customs Measures on Importation of Certain Products from Panama

349 Measures Affecting the Tariff Quota for Fresh or Chilled Garlic

351 Provisional Safeguard Measure on Certain Milk Products 